\title{
LA CETRERÍA EN LOS EJEMPLOS, SÍMILES Y METÁFORAS DE SAN VICENTE FERRER ${ }^{1}$
}

\author{
FALCONRY IN THE EXAMPLES, SIMILES AND METAPHORS \\ OF SAINT VINCENT FERRER
}

\section{CARMEL FERRAGUD}

Universidad Miguel Hernández, Elche

RiCARDO M. OLMOS DE LEÓN

Educación Permanente de Adultos, Requena

\begin{abstract}
Resumen: Vicente Ferrer utilizó en sus sermones numerosos y variados recursos para poder hacer inteligible su mensaje a su nutrido auditorio. Uno de estos recursos fueron las actividades venatorias $\mathrm{y}$, especialmente, la modalidad de caza con aves de presa. Por un lado, esta actividad le proporcionó elementos adecuados para construir las analogías que facilitarían la comprensión de la palabra de Dios. Sin embargo, por otro lado, parece que otras razones podrían explicar esta preferencia del predicador, más relacionadas con su propia experiencia y con la realidad de la sociedad a la que se dirigía. Y es que, además de las fuentes textuales, a menudo el padre Vicente recurrió a sus vivencias y, más aún, a aquellos aspectos de la vida cotidiana de su auditorio. A partir de las referencias que encontramos en los sermones de san Vicente podemos deducir que el predicador debía conocer de primera mano los diferentes aspectos relacionados con la cetrería, por lo que no debía resultarle difícil recurrir a algo familiar para construir las analogías que permitirían a su auditorio comprender los conceptos teológicos y conseguir la transformación de sus vidas, de acuerdo con la moral que el predicador pretendía implantar.
\end{abstract}

\begin{abstract}
Vincent Ferrer used in his sermons many and varied resources to make your message intelligible to its many listeners. One such resource was hunting activities and especially the form of hunting with birds. On the one hand, this activity was provided appropriate elements to construct analogies that facilitate the understanding of the word of God. However, on the other hand, it seems that perhaps other reasons may explain this preference of the speaker, more related to their own experience and the reality of the society to which he was going. And, in addition to the textual sources, father Vincent often drew on his own experience and, indeed, to those aspects of the daily lives of his audience. From the references we find in the sermons of saint Vincent we can deduce that the preacher should know first hand the various aspects of falconry, so it should not be hard to use something familiar to construct analogies that enable their audience understand the complex theological concepts and achieve the transformation of their lives, according to the moral that the preacher sought to implement.
\end{abstract}

\footnotetext{
${ }^{1}$ Este artículo se enmarca en el proyecto de investigación financiado por el Ministerio de Ciencia e Innovación "Corpus digital de la ciencia medieval en la Corona de Aragón y su contexto latino y románico: obras vernáculas, Arnau de Vilanova y Vicent Ferrer" (FFI2011-29117-C02, 2012-2014); y en el grupo de investigación consolidado por la Generalitat de Catalunya 2009 SGR 1452 "La Corona catalanoaragonesa, l'Islam i el món mediterrani'. También forma parte de la investigación en curso, sobre la medicina de las aves de presa durante la Baja Edad Media a través de los tratados de cetrería castellanos, que dará lugar a la tesis doctoral de Ricardo Olmos.
} 
Palabras clave: cetrería; sermones; predicación; exempla; Vicente Ferrer.
Keywords: falconry; sermons; preaching; exempla; Vincent Ferrer.

\section{SUMARIO}

1. Introducción.- 2. Las fuentes en la construcción de los sermones vicentinos.- 3. La cetrería en la sociedad bajomedieval.- 3.1. Una actividad muy presente en toda la sociedad.- 3.2. La cetrería y la iglesia.- 3.3. La simbología asociada al ave de caza y al cazador.- 4. La cetrería en los sermones vicentinos.- 5. Conclusiones.- 6. Bibliografía citada.

\section{INTRODUCCIÓN}

La figura del dominico valenciano Vicente Ferrer resulta sorprendente por la gran cantidad de trabajos que se han dedicado a su estudio. Su propia personalidad y la gran influencia social y política que tuvo sobre gobernantes de ciudades, papas y monarcas, además de su controvertido papel en torno a acontecimientos cruciales de la historia de la Corona de Aragón y de Europa Occidental, han hecho verter ríos de tinta ${ }^{2}$.

Si su biografía y todo lo que aconteció en torno a su culto y devoción a partir de su muerte y posterior santificación resultan extraordinariamente sugerentes ${ }^{3}$, la profundidad de su obra y de los sermones que nos han llegado reportados, o bien los sermonarios esquematizados en los que se inspiraban, hoy prácticamente editados en su conjunto, constituyen una fuente inagotable para estudios multidisciplinares (literatura, filología, historia).

Continuamente aparecen nuevos enfoques, perspectivas y aportaciones, que ponen en evidencia la extremada riqueza de este material ${ }^{4}$. Es en esta línea de aportación, de relectura de la obra vicentina, que debe ubicarse el presente trabajo. Concretamente, pretendemos aportar un análisis adicional de la figura del insigne predicador y, especialmente, de la forma en que usó uno de los elementos simbólicos más significativos de la sociedad medieval de los que se valió para construir sus sermones: la cetrería ${ }^{5}$.

En realidad, la profundidad y la riqueza de sus sermones son tan extraordinarias que a menudo requieren un análisis sistemático utilizándolos como piezas particulares. Sin embargo, nuestra aproximación ha sido mucho más extensiva, y después

\footnotetext{
${ }^{2}$ Un resumen de los debates suscitados en torno a la figura de Vicente Ferrer y sus influencias sobre la sociedad bajomedieval en A. Toldrà, Sant Vicent Ferrer, pp. 157-173.

${ }^{3}$ Las biografías sobre el santo y los escritos sobre su influencia posterior son numerosas. Citaremos aquí algunos de los estudios más recientes: F.M. Alarcón Menargues, Sobre la vida de Vicent Ferrer, pp. 253-255; A. Velasco, De València a Vannes, pp. 395-427; A. Esponera, San Vicente Ferrer; idem, El oficio de predicar, pp. 21-48.

${ }^{4}$ Resultan fundamentales los trabajos de Josep Perarnau en el volumen del "Arxiu de Textos Catalans Antics" (ATCA) dedicado a Estudis i inventari de sermons de Sant Vicent Ferrer, donde se identifican el conjunto de sermones y sermonarios relacionados con el predicador valenciano y los tipos de estudio a que han dado lugar.

${ }^{5}$ Por simplicidad, hemos decidido emplear este término (y sus derivados) pese a que la expresión más habitual en la Edad Media era la de "caza con aves" o, simplemente, "caza". El término cetrería, con sus variantes y derivados, aunque conocido y empleado en la Edad Media, extiende su uso en la Edad Moderna y es el empleado en la actualidad para referirse a esta modalidad cinegética. Sobre éste y otros términos relacionados, véase J.M. Fradejas, Notas léxicas, pp. 149-158.
} 
de un vaciado de todos los sermones reportados y los sermonarios publicados, hemos podido obtener una rica información relativa a la caza con aves que puede resultar útil en un doble sentido. Por un lado, como elemento demostrativo de un tipo muy particular de fuentes y recursos utilizados en la predicación y, por otro, como muestra de la importancia social de este tipo de caza, reflejada en el uso que el predicador hizo de ello 6 .

\section{LAS FUENTES EN LA CONSTRUCCIÓN DE LOS SERMONES VICENTINOS}

Son abundantes los trabajos que se han ocupado de estudiar la estructura y el particular contenido de los sermones de los predicadores durante la Edad Media, y en particular de los del dominico Vicente Ferrer, así como los recursos retóricos y oratorios que emplearon ${ }^{7}$. Sin embargo, la riqueza extraordinaria de las fuentes empleadas por un predicador como el dominico valenciano, los recursos diversos a la hora de elaborar sus numerosos sermones son tantos, que aún quedan aspectos poco conocidos o que han recibido una atención muy parcial.

Construir un sermón era una tarea laboriosa a la cual el predicador solía dedicar la tranquilidad de la noche. Solo o con algún colaborador buscaba entre sus fuentes para confeccionar aquella homilía que más le interesaba para el día y el auditorio que tendría delante ${ }^{8}$. Durante el siglo XIV habían proliferado los manuales de ayuda o Ars Praedicandi, necesarios para hacer frente a las nuevas demandas del público al que se enfrentaban los frailes mendicantes, tan dados al oficio de la predicación. La tarea que les era encomendada era notable. Auténticos alfabetizadores de la fe y de las costumbres, tuvieron una influencia extraordinaria. Su labor fue cada vez más exigente y debieron realizar un gran esfuerzo intelectual para construir sus homilías, de las que el sermón era una parte esencial 9 .

De entre todas las partes del sermón, sin duda, configurar la dilatatio o ampliación, una vez trazada la temática y el esquema general, requería de una pericia intelectual que se debatió entre el conocimiento y uso de textos muy diversos, que se fueron acumulando con el tiempo desde los inicios de la predicación altomedieval, y la aportación personal y singular de cada individuo, en función de sus experiencias y gustos, con el fin de acercarse de la mejor forma posible a su auditorio. Se trataba de incorporar constantemente nuevos elementos que despertaran la atención y que conmovieran ${ }^{10}$.

Los predicadores medievales disponían de un amplio arsenal de materiales con el fin de amplificar su sermón, tal y como les indicaban los manuales del Ars Praedicandi. En el caso de Vicente Ferrer, éstos iban desde textos con carácter estrictamente religioso, tales como la Biblia, y especialmente el Nuevo Testamento, o los

\footnotetext{
${ }^{6}$ Con todo, somos conscientes de los riesgos advertidos de usar los ejemplos como elemento extraído del sermón que les da sentido, en el tono expresado en C. Delcorno, Bernardino narratore, p. 127. Sin embargo, nosotros los contextualizaremos dentro de la temática y el ejemplo para el que fueron creados, y no como piezas literarias por sí mismas.

${ }^{7}$ Para una contextualización del sermón vicentino en el marco general de la predicación bajomedieval europea, véase T. Martínez, Alguns aspectes, pp. 109-133; idem, Aproximació als sermons, pp. 51-77; M. Sanchis Guarner, Estudi preliminar, pp. 7-35; P.M. Cátedra, Sermón, sociedad y literatura, pp. 83-99. Las peculiaridades de su oratoria en J. Fuster, Notes per a un estudi, pp. 87-185.

${ }^{8}$ J. Sanchis Sivera, Quaresma de Sant Vicent, p. XXVI.

${ }^{9}$ F. Eiximenis, Art de predicació, pp. XXV-LXI.

${ }^{10}$ T. Martínez, Aproximació als sermons, pp. 76-77.
} 
escritos patrísticos (san Dionisio, san Jerónimo), pasando por textos filosóficos (Aristóteles, Platón, Boecio, Vegecio), teológicos (La Summa Theologiae de santo Tomás de Aquino, las Etimologiae de san Isidoro), jurídicos -debemos tener en cuenta su origen familiar- y enciclopédicos muy conocidos, como el De animalibus de Alberto Magno, bestiarios, lapidarios, herbarios y otros. Y es que Ferrer fue un estudioso apasionado, amante de los libros y de las bibliotecas, que abominaba la ignorancia, sobre todo de los profesionales (médicos, juristas, notarios...), y que aplicó estrictamente a su obra los principios del escolasticismo en el que se había formado ${ }^{11}$. Sin embargo, estos textos, que bien conocía, no fueron citados explícitamente casi nunca. Ésta fue una característica propia de los predicadores del siglo XV frente a los de los siglos anteriores, que sí prefirieron citar permanentemente y con cierta exactitud las fuentes de donde habían bebido sus sermones ${ }^{12}$. Pero, además, en ambos casos, los predicadores huyeron casi siempre de la cita textual, y lo que es más común, como veremos más adelante, buscaron sus ejemplos en historias contemporáneas, episodios conocidos, costumbres y supersticiones cercanas a su auditorio, es decir, buscaron popularizar sus contenidos ${ }^{13}$.

El riquísimo y apabullante repertorio de ejemplos (exempla), símiles ( litudines), metáforas e imágenes utilizadas en los sermones, que se confunden a veces unos con otros, se construyeron a partir del conocimiento profundo de estos materiales y de su reelaboración ${ }^{14}$. Y eso que podemos considerar que no necesariamente todo este material y recursos literarios del predicador fueran recogidos siempre y con integridad, y que tal vez esto quedó a criterio del reportador ${ }^{15}$. De hecho, el predicador no necesitaba acudir directamente a las fuentes ya que, sobre todo desde el siglo XIII, diversos autores se habían dedicado a compilar y reunir auténticas colecciones de exempla. Los repertorios fueron creciendo y haciéndose cada vez más útiles y sencillos en su manejo. El predicador podría así escoger rápida y eficazmente el material

${ }^{11}$ M. Beuchot, Pensamiento filosófico, pp. 33-35. De él se dijo que no cesó en su estudio ni siquiera durante sus viajes de predicación: S. Fuster, Proceso de canonización, pp. 31, 152. De hecho, llegó a crear un régimen de sanidad para el predicador, en el que se aconsejaba sobre los hábitos adecuados para poder estudiar. Véase la traducción castellana del tratado en A. Robles, Tratado de la vida espiritual, en Obras y escritos, pp. 312-323. Aquí se ofrece una lista de ediciones y traducciones, así como un breve estudio sobre la composición, contenidos e influencias utilizadas por Ferrer en la elaboración del tratado.

${ }^{12}$ J. Ziegler, Medicine and religion, pp. 208-211. El caso de Ferrer, en F. Carbó, Notes sobre les estratègies, pp. 139-152. Con Vicente Ferrer, por ejemplo, comparte esta característica otro insigne predicador como fue Bernardino de Siena. C. Delcorno, Exemplum e letteratura, pp. 129-130.

${ }^{13}$ Con todo, debemos matizar la afirmación que siempre se ha mantenido en torno al contenido popular de los sermones vicentinos, ya que la erudición y la complejidad se encuentran también presentes en sus sermones. Hay que tener en cuenta que sus auditorios fueron bien distintos y el predicador se acopló siempre a ellos. T. Martínez, Aproximació als sermons, pp. 125-126.

${ }^{14}$ Aunque aquello que definía el "exemplum” era su carácter moral y ejemplarizante para el cristiano, así como su estructura narrativa corta, detrás de esta palabra se escondieron diversos recursos literarios, sin que necesariamente siguieran un esquema narrativo. El propio Tubach recogió en su famoso catálogo símiles y referencias diversas que tenían también una función ejemplar. F. Tubach, Index exemplorum, p. 520. A veces "símil", "cuento", "caso", "milagro" o "historia" se utilizaron con la misma finalidad y funcionaron como sinónimos. F. Kemmler, Exempla in context, pp. 61-62. En el caso de Vicente Ferrer, "exemple", "miracle", "semblança", "rahó" y "figura" constituyen términos que utilizó para designar lo que entendemos por "ejemplo". Los símiles ("semblança"), muy habituales en el sermonario del predicador valenciano, se convertirían en un medio ideal para explicar los misterios de la religión, y muchas veces serían de mayor uso que los propios ejemplos (tres por sermón frente a dos ejemplos). V. Almazan, L’exemplum, pp. 300-304.

${ }^{15}$ F. Morenzoni, Exempla et predication, pp. 272-273. 
indicado para el tema sobre el que quisiera hablar a sus feligreses. En tiempos de Vicente Ferrer ya había disponibles un amplio elenco de estas colecciones ${ }^{16}$.

En realidad, en el siglo XIII se produjo un cambio en las fuentes empleadas por los predicadores: la Glossa ordinaria, las obras de los padres de la iglesia y la Biblia moralizada, aunque no cesaran de usarse, dejaron paso a textos profanos, entre los que destacan las enciclopedias y bestiarios medievales ${ }^{17}$. El mundo natural y, especialmente, las "propiedades" de los animales se convirtieron en recurso inagotable a la hora de construir las analogías que facilitaran la comprensión del mensaje teológico. Las criaturas de la naturaleza fueron un sujeto apto para abrir los espíritus más rudos, ya que cuando el discurso revelado por las sagradas escrituras no conmovía a un auditorio se podía llamar la atención con el uso de elementos diferentes y novedosos. Y así, los comentarios acerca de las alegorías con animales, plantas y otros elementos de la naturaleza no fueron sino una invitación al predicador para abordar temas inusitados y conseguir muchas sugerencias para la amplificación de sus sermones ${ }^{18}$.

También el padre Vicente Ferrer recurrió a estas fuentes, como muestra un sermón castellano:

una vegada un can furtó a un carniçero una pieça de carne e fuesse con ella e ovo de passar un rrío. E al passar del rrío, la carne que llevava en la boca fizo sonbra, e él pensó que fuese otra pieça de carne, e soltó la que llevava por tomar aquélla; e assí perdió la carne que levava ${ }^{19}$.

Si comparamos este pasaje con el Bestiari catalán observaremos que se recoge una información sobre la naturaleza de los perros y su significado que nos demuestra que sin duda fue ésta la fuente a la que recurrió nuestro predicador:

que com ell passa per algun pont e porta formatge o pa o carn en la bocha, o altra cosa, e veu la ombra d'aquell formatge en l'ayga e li sembla major que aquella que porta en la bocha, lexa caer aquella que té en la bocha e gita's en l'ayga, e pert lo formatge que tenia ${ }^{20}$.

En una de las pocas ocasiones en que el padre Vicente citó su fuente explícitamente, concretamente en uno de sus sermones predicados en Castilla, se refirió al libro de Bartolomé de Glanville o Bartolomé el Inglés (Bartolomeus Anglicus). Se trata de una historia natural que estuvo bien presente en el ámbito catalanoaragonés ya en los inicios del siglo XV, como lo demuestra el interés puesto por el rey Martín el Humano en 1404 y 1405. Así, el 17 de agosto de 1404 pidió al baile general de Ara-

16 Basta tener en cuenta los 5.400 exempla que fueron recogidos por Frederic Tubach a partir de 37 colecciones, para tener una idea de la importancia y magnitud de este "género". F. Tubach, Index Exemplorum. Sobre los exempla y su uso en los sermones véase C. Bremond, J. Le Goff, J.C. Schmitt, L'«exemplum», pp. 147-164; J. Berlioz, Le récit efficace, pp. 113-146. Ejemplos del uso de héroes en los exempla, en W.J. Aerts, M. Grosman, Exemplum et similitudo. Para el caso español véase F. Bravo, Arte de enseñar, pp. 303-327. Son también útiles las introducciones a ediciones como las de V. de la Torre, J. Lozano (eds.), Gesta Romanorum, pp. 24-38; F. Kemmler, Exempla in context, pp. 60-90; M. Ambrosio Sánchez, Un sermonario castellano. Para el caso concreto de Ferrer, véase V. Almazan, L'exemplum, pp. 288-297.

${ }^{17}$ G. Parussa, La nature "merveilleuse » des animaux, p. 144; V. de la Torre, J. Lozano (eds.), Gesta Romanorum, pp. 38-39.

${ }^{18}$ B. Van den Abeele, L'allégorie animale, p. 131.

${ }^{19}$ P.M. Cátedra, Sermón, sociedad y literatura, p. 400.

${ }^{20}$ Bestiaris, vol. II, p. 33. 
gón que le enviase, entre otras cosas, un libro que contenía este texto. El rey deseaba ansiosamente recibir el manuscrito desde tiempo atrás, aunque no había tenido fortuna para acceder a él. Por eso, el 28 de agosto del siguiente año volvió a reclamar el volumen al merino de Zaragoza, diciendo que, en este caso, se debía pagar un precio e que.l haviesse del prehicador ${ }^{21}$. Desgraciadamente, no sabemos a qué individuo se refería, pero el hecho nos indica el interés que habían puesto en él los profesionales de la predicación.

Concretamente, el libro 18 de Bartolomé el Inglés versaba sobre los animales, y fue éste el que sirvió de inspiración a nuestro dominico para hablar de un tipo de víboras llamadas tigris, adecuadas para hacer medicinas. Las particularidades etológicas de esta víbora, puramente fantásticas, fueron desveladas en el sermón ${ }^{22}$.

En otras ocasiones, podemos adivinar la procedencia de sus fuentes. Este sería el caso del De animalibus de Alberto Magno. En el capítulo De cane, el autor se refirió a la capacidad que tenían los perros de sanarse a sí mismos gracias a las propiedades curativas de su saliva ${ }^{23}$. Siguiendo con este símil, en diversas ocasiones Ferrer comparó a los predicadores con los perros. En primer lugar, porque con sus ladridos, o predicaciones, advierten a las personas y ahuyentan a los diablos, como los perros hacen lo propio con los lobos respecto del ganado. En segundo lugar, porque así como los perros curan las heridas lamiendo con lengua medicinal, de la misma forma los predicadores tienen una lengua medicinal $y$, lamiendo al que predican, le curan las heridas extirpándoles los vicios ${ }^{24}$.

Con todo, debemos advertir que Vicente Ferrer manejó a su antojo y conveniencia los materiales de los que disponía, de tal forma que su posición frente a ellos se convierte en ambigua y contradictoria. Este sería el caso ante la cultura clásica profana y la contemporánea ${ }^{25}$. Así, nuestro predicador se mostró contrario al estudio de la filosofía como saber profano y autónomo. Para éste, las artes liberales y la filosofía natural no tenían valor si no era como medio de interpretación de la Biblia, donde reside la única ciencia que el creyente debe poseer para salvarse. Toda aquella filosofía que él consideró como "servidora" de la "teología" fue apropiada y aprovechada siempre que pudo servir a sus fines, que eran, más que explicar teología, conseguir la reforma de las costumbres morales del pueblo cristiano ${ }^{26}$. Ferrer utilizará, por ejemplo, el esquema de las siete artes liberales -que se encuentran presentes en la excelencia de la doctrina de Cristo- como imagen, pero advirtió que sobre nada de aquello, que conocía perfectamente, predicó el hijo de Dios, pues lo único importante es qué debemos hacer para alcanzar el paraíso ${ }^{27}$. Igualmente, la presencia de los cuatro elementos aristotélicos y las alusiones al "filósofo" serán permanentes.

\footnotetext{
${ }^{22}$ La antigua tradición de los encantadores de serpientes que hacían sonar sus instrumentos para controlar a los reptiles aparece en el bestiario catalán. En éste se nombra la "aprís", una serpiente que se tapa una oreja con la cola y que pega la otra al suelo para no escuchar el instrumento del encantador. Ahora bien, en el bestiario el sonido no lo producía el demonio sino el predicador, que pretendía hacer llegar la voz de Dios al cristiano que hace oídos sordos. Bestiaris, vol. I, pp. 81-82.

23 "Curare autem vulnera sua et aliena dicuntur lingua et si lingua tangere non possunt, pedem saliva infectum locum laesum tangunt et sanant”. J. Loncke, La Practica canum, pp. 15 y 98.

${ }^{24}$ Vicente Ferrer, Sermonario de San Vicente Ferrer, p. 123.

${ }_{25}$ T. Martínez, Aproximació als sermons, p. 29; V. Martines, Sant Jordi, p. 102.

${ }^{26}$ J.E. Rubio, Salvar Aristòtil?, pp. 189-191; A. Esponerá, El oficio de predicar, pp. 87-104.

27 Vicent Ferrer, Sermonario de Perugia, p. 425; idem, Sermons, vol. V, p. 213.
}

${ }^{21}$ Ambos documentos fueron publicados en A. Rubió i Lluch, Documents per l'història, § 493 y 497. 
Sin duda, una de las cuestiones que merece todavía una especial atención en los sermones vicentinos es el uso de los conocimientos científicos. Debemos afirmar que las referencias a la ciencia y a las artes liberales son muy abundantes en los sermones y además relativas a numerosos campos del conocimiento ${ }^{28}$. Y, cómo no, nuestro predicador demostró tener gran interés por la astronomía y la astrología, como ciencias que eran capaces de describir la estructura del universo, con el sol, la luna y los diferentes planetas y cielos conocidos, y la bóveda celeste fija con las estrellas. Pero que también eran capaces de dar explicación a determinados fenómenos climatológicos (lluvias, granizadas) o a las epidemias ${ }^{29}$.

Con todo, merece un lugar muy destacado en los sermones vicentinos la medicina $^{30}$. El padre Vicente Ferrer utilizó con frecuencia algunos de los problemas a los que la humanidad se había enfrentado, derivados de su propia naturaleza. De este modo, la enfermedad, el dolor, la muerte, la pérdida de la salud, su mantenimiento y su recuperación a través de los distintos remedios y los practicantes con los que contó aquella sociedad, ya fueran los aceptados por él cómo válidos (medicina galenista, curanderos, físicos, barberos...) como aquellos sospechosos de pertenecer al diablo y al pecado (fórmulas supersticiosas, oraciones, ensalmos...), hicieron acto de presencia en sus sermones. El dominico utilizó aquel contexto para diluirlo en sus predicaciones y acercarse mejor a los sentimientos y el entendimiento de sus oyentes ${ }^{31}$.

Efectivamente, en el tema de la medicina, como en tantos otros, el predicador se debatió entre la materia doctrinal y la experiencia cotidiana del oyente. Pero el hecho de que muchas de estas realidades intelectuales estuvieran muy alejadas de la mayor parte del auditorio, hizo que Ferrer se decantara por diferentes recursos retóricos que evocaban situaciones que partían de la experiencia concreta de sus oyentes y que describían costumbres, maneras de hacer o de hablar que aludían a la vida cotidiana, tal y como habían advertido las artes de predicación y se puede comprobar en otros predicadores ${ }^{32}$. Ferrer apelaba a una parte del universo familiar de sus oyentes, muchas veces con una gran carga visual. Así, por ejemplo, utilizó en ocasiones las referencias a las pinturas y a las vidrieras que, como es bien conocido, configuraron programas iconográficos que pretendieron iluminar

${ }^{28}$ La geometría, en Vicente Ferrer, Sermonario de San Vicente Ferrer, p. 615. También la música se hace presente cuando compara los gritos proferidos por los martirizados con los sonidos de diferentes tipos de instrumentos musicales. Vicent Ferrer, Sermons, vol. IV, pp. 204-205. En cierta ocasión comparó los tubos de un órgano con las distintas formas de predicar según a quien se dirige el sermón. Vicente Ferrer, Colección de Sermones de Cuaresma y otros según el Manuscrito de Ayora, pp. 442-443.

29 En un sermón predicado en la Cuaresma de Valencia, justificó desde una perspectiva científica o natural y otra teologal el por qué se había ordenado tradicionalmente por la iglesia el hacer determinadas rogativas y procesiones con letanías. V. Ferrer, Sermons, vol. VI, p. 108. Sin embargo, el conocimiento de todo ello era limitado para el hombre, y era así que emergía triunfadora la fe para dar "explicación" de todo ello. J. Sanchis Sivera, Quaresma de Sant Vicent, pp. 7-8.

${ }^{30}$ C. Ferragud, La difusión de los conocimientos, pp. 461-466. También algún autor ha interpretado la realidad de la sociedad medieval trazada por Ferrer en sus sermones, en la clave de cuerpo enfermo. J.A. Ysern-Lagarda, Sant Vicent Ferrer, p. 85. Un primer acercamiento, si bien muy básico y estrecho, a la realidad médica en los sermones vicentinos en J. Chabás, Las costumbres y la medicina, pp. 617-620. Actualmente, uno de nosotros (Ferragud) trabaja en una monografía sobre la ciencia y la medicina en los sermones vicentinos.

${ }^{31}$ Vicente Ferrer era heredero de una larga tradición, iniciada en el siglo XII, en la que los predicadores utilizaron como recurso la medicina, que tan bien se ajustaba como símil y ejemplo al mensaje que se quería transmitir. J. Ziegler, Medicine and religion, pp. 176-213.

${ }^{32}$ F. Eximenis, Art de predicació, pp. 35-36; F. Morenzoni, Exempla et prédication, pp. 271-272. 
visualmente al pueblo cristiano sobre los contenidos de su fe, analfabeto como era en su mayoría 33 .

Ferrer demostró tener amplios conocimientos sobre numerosos ámbitos y aspectos de la sociedad de su época, desde la corte real y su organización, el ejército, la guerra y los métodos empleados en el combate, hasta los ambientes urbanos más populares y en ocasiones más sórdidos, como el hostal y la taberna, y lo relativo al mundo rural ${ }^{34}$. La experiencia mundana de Ferrer se dejó sentir con gran intensidad en sus sermones, y la aplicó intensivamente para sintonizar y llegar con la mayor facilidad a sus fervientes admiradores. Cualquier detalle parecía útil para que la hábil y ágil mente del predicador lo convirtiera en ejemplo para transmitir la complejidad de su mensaje y transformar las actitudes de aquella gente. Tan profunda resulta su radiografía de los escenarios y los personajes del medioevo, que ello ha permitido un acercamiento a numerosas realidades de aquella sociedad ${ }^{35}$.

En este sentido, la cetrería sería utilizada en sus sermones en numerosas ocasiones. Aquella práctica tan común y difundida en la Baja Edad Media, constituye otra clara muestra del recurso de nuestro predicador a su propia experiencia y a la realidad cotidiana de la sociedad en la que vivió. Sin embargo, antes de analizar en detalle el uso que hace san Vicente de la cetrería en sus sermones, resulta necesario conocer algunos detalles de esta técnica de caza y de su presencia en la sociedad bajomedieval.

\section{LA CETRERÍA EN LA SOCIEDAD BAJOMEDIEVAL}

La cetrería, modalidad de caza en la que el hombre se vale de aves de presa adiestradas para capturar otros animales, se encontraba ya plenamente establecida en los territorios de la Europa Occidental en la Baja Edad Media ${ }^{36}$. La captura de halcones, azores y gavilanes, su adiestramiento y cuidados, estaban lejos de ser tareas sencillas, y requerían una precisa formación. Incluso la propia acción de la caza requería experiencia para ser concluida con éxito. La necesidad de adquirir los conocimientos específicos de esta arte e çiençia de la caça de las aves ${ }^{37}$ debió contar entre los motivos de la aparición y gran difusión de tratados de cetrería en la Baja Edad Media, en los que se recogían y exponían los diferentes aspectos relacionados con el arte, desde la alimentación y los cuidados médicos de las aves (primeros tratados, en latín) hasta la elección de las mismas, su adiestramiento y la caza propiamente dicha (tratados tardíos, en lenguas vernáculas) ${ }^{38}$. Además del

33 Un ejemplo extraordinario del papel moralizante del arte son las vidrieras de la catedral de Chartres. J.W. Williams, Bread, Wine and Money, especialmente en los capítulos 3, 4 y 5. Sobre la valoración que da Vicente Ferrer a la pintura, véase A. Toldrà, Sant Vicent contra el pintor, pp. 37-56.

${ }^{34}$ Sobre la guerra y el ejército en J. Sanchis Sivera, Quaresma de Sant Vicent Ferrer, p. 142. Una descripción de los miembros de la casa real comparados con las distintas categorías del pueblo de Dios en M. Llop, San Vicente Ferrer, pp. 68-69.

${ }^{35}$ Véase un estudio de los distintos colectivos que integraban la sociedad, así como aspectos profesionales, laborales y económicos en M. Llop, San Vicente Ferrer. Para la prostitución, la violencia y el orden social, véase R. Narbona, Pueblo, poder y sexo, pp. 79-121.

${ }^{36} \mathrm{Su}$ difusión por Europa se produjo en la Alta Edad Media, de mano de los pueblos germánicos por el norte y de mano de los árabes por el sur. Véase J.M. Fradejas, Pasado y presente, pp. 17-20; idem, La cetrería en el mundo iberoamericano, pp. 35-38.

${ }^{37}$ Expresión empleada por el canciller Pero López de Ayala, en M. Delgado, Edición crítica del Libro de la caza de las aves, p. 63.

${ }_{38}$ Así justifica el canciller Pero López de Ayala la redacción de su obra, en pleno siglo XIV: "E quando yo començé a afanar con el neblí, mucho me pluguiera aver fallado un pequeño escripto 
recurso a los libros, el aprendizaje con otros cazadores o maestros debió ser la forma más habitual de adquirir los conocimientos necesarios y quizá la única antes del inicio de la importante producción de los tratados de cetrería, que tuvo lugar en el siglo XII, aunque, sin duda, el intercambio de experiencias entre cazadores debió siempre contribuir a la difusión de los conocimientos y a la evolución del arte de la caza con aves.

El adiestramiento de estas aves giraba en torno a una idea fundamental: el control preciso del hambre del ave. Una gran sensibilidad, experiencia y pericia eran necesarias para dosificar, en calidad y cantidad, el alimento que se proporcionaba al ave y lograr el estado óptimo para su manejo y para la caza ${ }^{39}$. Por ello, para tener aves de cetrería y cazar con ellas, no bastaba con superar un proceso de aprendizaje, sino que se requerían unas cualidades personales muy particulares y una cierta habilidad natural, además de una inclinación a la caza, como pusieron de manifiesto los autores de los antiguos tratados de cetrería ${ }^{40}$.

Para adiestrar estas aves y cazar con ellas eran necesarios, además, una serie de útiles específicos y unas instalaciones adecuadas. Guantes, caperuzas, cascabeles, pihuelas, lonjas, señuelos, eran algunos de los instrumentos empleados por los halconeros medievales para manejar las aves de caza ${ }^{41}$. Esta actividad tan especializada produjo un riquísimo vocabulario técnico, indispensable para poder expresar con precisión todos los conceptos que exigía el arte, desde las características de las aves empleadas hasta los útiles necesarios para manejarlas, los síntomas de sus enfermedades o las técnicas de caza ${ }^{42}$. También debe destacarse la importancia de la práctica médica que siempre estuvo estrechamente asociada al manejo de halcones, azores y gavilanes. Y es que mantener estas aves en cautividad exigió recurrir de forma continua a la medicina para conservar su salud y para curarlas de las enfermedades, heridas y fracturas que con frecuencia sufrían ${ }^{43}$.

tal como este, por do me podiera regir e governar e guardar de fazer algunos yerros en la caça que fize e con que dañé muchos falcones, e yo era sin culpa ca non sabía más e quando me aconpañava con falconeros que sabían el arte parava mientes e por ventura en un mes aprendía un capítulo de lo que veía", en M. Delgado, Edición crítica del Libro de la caza de las aves, p. 150. Sobre las obras de caza en la Edad Media y su evolución, véase B. Van den Abeele, La littérature cynégétique. pp. 31 y ss.

39 Tanto los tratados de cetrería como las enciclopedias, en sus apartados correspondientes a las aves de presa, advierten sobre este aspecto del gobierno de las aves. Por ejemplo, en un tratado catalán se explica: "Per qu·és mester que tot caçador se avise e que, tantost, mijant lo mes de febrer, abaxets vostre ocell e que.n cacets ben tenprat e que·l tingats ben pijat, pus fort que no solíeu, e que.l façats caçar ab fam. E, si l'abaxau, serets-ne senyor e senyorejarets-vos a ell, si no desconéxer-vos ha, per què tot caçador se deu avisar e-s deu entricar de tenir lo seu aucell gras en lo temps que u ha mester ho en cominal carn o magre, segons lo temps", en M. Garcia, C. Arronis, H. Càmara (eds.), Libre de animals de caçar, ff. 20r-20v.

${ }^{40}$ Véase, por ejemplo, el apartado "De falconario qualis debet esse", de la obra de Federico II, donde se dan, incluso, indicaciones sobre las cualidades morales del halconero. A.L. Trombetti (ed.), De Arte venandi cum avibus, pp. 346 y ss.

${ }^{41}$ Sobre los útiles e instalaciones véase, por ejemplo, J.M. Fradejas, Pasado y presente, pp. 66-89.

42 Para la lengua castellana hay un estudio en M. Álvarez-Buylla, El vocabulario de la cetrería.

${ }^{43}$ Prueba de ello es que todos los tratados de cetrería medievales dedican una parte importante, cuando no toda la obra, a las enfermedades de las aves y a los remedios para curarlas. Sobre el contenido de las obras castellanas, véase J.M. Fradejas, Literatura cetrera de la Edad Media y el Renacimiento español, pp. 7-10. Para las obras latinas, B. Van den Abeele, La fauconnerie au Moyen Age, pp. 11-12. 


\subsection{Una actividad muy presente en toda la sociedad}

Las aves de presa y su empleo en la caza han tenido diferentes funciones a lo largo del tiempo y en los diferentes territorios en los que se ha desarrollado esta relación entre hombres y rapaces. Aparte de los evidentes objetivos utilitarios de cualquier modalidad de caza, que son obtener carne y pieles o eliminar animales nocivos, la cetrería jugó en la sociedad medieval un importante papel en la formación de los jóvenes de la aristocracia, además de constituir una importante actividad de recreo y, en cualquier caso, un signo de distinción y de poder ${ }^{44}$.

Es indicativo de la importancia que tuvo esta actividad en la Edad Media, tanto en los reinos peninsulares como en el resto de Europa Occidental, las numerosas huellas que ha dejado en la literatura medieval y en otras formas de manifestación artística, además de los propios tratados de caza que ya hemos mencionado ${ }^{45}$. Más aún, las numerosas referencias a las aves de caza que salpican los documentos de la época no hacen sino confirmar la presencia de la cetrería en múltiples ámbitos de la sociedad medieval.

Una idea bastante extendida es que, en la sociedad medieval occidental, la posesión de aves y su empleo para la caza estaba limitada a la nobleza. Azores, gavilanes y halcones de diferentes tipos ${ }^{46}$ eran capturados, comprados o recibidos como obsequio por reyes y nobles, que llegaron a poseer un número elevadísimo de dichas aves. Para custodiarlas, las casas reales y señoriales contaban con varios halconeros, normalmente bajo el mando de un halconero mayor, y éstos eran los responsables de guarnecer a las aves de los utensilios necesarios para su manejo, de alimentarlas, adiestrarlas, mantenerlas sanas y curarlas de sus enfermedades ${ }^{47}$.

Prueba de la importancia que la nobleza daba a estas aves y a la caza con ellas es el gran dispendio que hacían para adquirir y mantener dichas aves o los utensilios propios del arte que, a menudo, estaban elaborados con materiales preciosos. Tanto las aves como los útiles empleados en su manejo constituían un obsequio muy especial $\mathrm{y}$, frecuentemente, una manera de sellar acuerdos ${ }^{48}$. Algunos monarcas llegaron a recibir un sobrenombre por su afición a la caza, como Juan I de Aragón, a quien se le conoció como Joan lo Caçador y, en algunos casos, la afición llegó a tales extremos que fue calificada de vicio ${ }^{49}$.

Sin embargo, un significativo número de referencias dispersas sugieren que la cetrería no estaba tan limitada a los grupos sociales más elevados y que esta forma de caza, de ostentación y de poder, pudo convivir con otra práctica mucho más modesta. Ahora bien, el principal problema para el estudio de la caza con aves por parte de gente

44 Pero López de Ayala compuso su tratado "para exerçiçio de los omes por los tirar de oçio e pensamiento e puedan aver entre los sus enojos e cuidados algund plazer e recreamiento sin pecado". M. Delgado, Edición crítica del Libro de la caza de las aves, pp. 59-60. Sobre las funciones de la cetrería y la caza, véase J.M. Fradejas, Pasado y presente, pp. 24-25; R.S. Oggins, The kings and their hawks, pp. 109-112.

${ }^{45}$ Algunas muestras de arte medieval inspirado en la caza con aves pueden verse en Ch.A. de Chamerlat, La fauconnerie et l'art, pp. 82-103.

46 Intentamos evitar el empleo del término "especie" que contaminaría, con el significado del concepto de la taxonomía moderna, la clasificación medieval de las aves.

${ }^{47}$ Por ejemplo, en las Ordinacions de Pedro el Ceremonioso se estipulaba que la casa real debería contar con un halconero mayor, seis halconeros y dos cazadores o guardas de perros, cada uno de los cuales tenía unas funciones asignadas. Véase F.M. Gimeno, D. Gozalbo, J. Trenchs (eds.), Ordinacions de la Casa i Cort de Pere el Cerimoniós, pp. 82-85.

${ }^{48}$ I. Beceiro, La caza y la alta nobleza bajomedieval, pp. 77 y ss.

49 J.M. Fradejas, Pasado y presente, p. 25. 
de condición más humilde reside en que muchas facetas de la vida cotidiana de los integrantes de los niveles inferiores de la sociedad medieval apenas han dejado huella en las fuentes habituales ${ }^{50}$. A esto se debe que no se haya insistido sobre este punto.

Menciones explícitas a la práctica de la cetrería por parte de personas de diferente condición las encontramos ya en algunos tratados de caza. Juan Manuel explica que las menos aves que el grant señor deve traer para fazer caça conplida deven seer dieziocho, ya que si non lo fazen, caçarían com[o] otro omne, mas non como pertenesçe caçar al grant señor ${ }^{51}$. Y es que nobles y señores fueron un modelo a imitar por la sociedad. De este modo, si en un principio la posesión y la caza con aves ya fue, en sí misma, un signo de distinción social, al ir extendiéndose esta práctica en la sociedad en el intento de imitar a los grupos superiores, éstos debieron trasladar el signo de distinción al número de aves poseídas y a su diversidad, rareza y valor o al resto de elementos que rodeaban a las aves (utensilios decorados, etc.) y las partidas de caza $^{52}$. Algunas aves poseían características que las hacían accesibles a muchas más personas. Este sería el caso de los bornís, que tenían un valor económico muy inferior al de otros halcones más apreciados (neblís, baharís, gerifaltes) y que eran mucho menos delicados y costosos de mantener, por lo que estarían al alcance de gente de condición más modesta ${ }^{53}$. En algunos territorios de la Corona de Aragón, en concreto en las islas Baleares, se ha podido documentar la posesión de halcones y la práctica de la cetrería por parte de personas de un nivel social menos elevado y resulta llamativo que en algún documento de la época se describa a los campesinos montando a caballo y portando halcones ${ }^{54}$. Precisamente aquí se ha documentado la existencia de afaitadors de falcons, que adiestrarían por encargo las aves de diferentes cazadores que, quizá por su condición más modesta, no podrían mantener a su servicio varios halconeros para atender gran número de aves ${ }^{55}$.

El hecho de que muchos aspectos relacionados con la cetrería y con las aves de caza fueran regulados también apoya la idea de una mayor difusión social de esta actividad. El precio de las aves de caza, así como las condiciones y los tiempos en que éstas podían capturarse, el precio de los utensilios propios del arte, los periodos de veda y las zonas en que se podía cazar con aves eran habitualmente objeto de regulación, bien en Fueros, en legislación de Cortes o en ordenanzas municipales. A menudo, la caza con aves estaba sometida a menores restricciones en el tiempo y el espacio que otras modalidades cinegéticas. Resulta especialmente llamativo que en

${ }^{50}$ La práctica de la cetrería por parte de personas no pertenecientes a la nobleza ya ha sido apuntada en varias ocasiones, como en R.S. Oggins, The kings and their hawks, pp. 113-126 o en B. Van den Abeele, La fauconnerie au Moyen Age, pp. 165-171.

51 J.M. Fradejas (ed.), Don Juan Manuel y el “Libro de la caza”, p. 191.

52 R.S. Oggins, The kings and their hawks, p. 117.

${ }^{53}$ Beltrán de la Cueva, en las glosas para el tratado de cetrería de Juan de Sahagún escribió: "Estos burnis es buen linaje de falcones, porque son poco costosos para los fidalgos que no pueden cazar con otras aves, y aun ayúdales á la costa de la carne". J. de Sahagún, Libro de cetrería, p. 22. Prueba de que eran aves menos apreciadas es que, en El libro de la caza, "De los bornís non quiso don Johan fablar mucho porque se non paga mucho de la su caça nin de las sus maneras". J.M. Fradejas (ed.), Don Juan Manuel y "El libro de la caza”, p. 144.

${ }^{54}$ J. Bover, R. Roselló, Alguns aspectes de la falconeria àrab, p. 72.

${ }^{55} \mathrm{La}$ figura del adiestrador de halcones es poco conocida. La información de las referencias para las Baleares se encuentra en J. Bover, R. Rosselló, La falconeria a les Balears, pp. 119-121. Breves referencias en documentos medievales, como que el hostalero de Valencia, Domingo Conill, tenía entre sus bienes "dos guants ab quatre cascavells e dos capells de falquó", dan indicio de que personas de condición más sencilla y, desde luego no pertenecientes a la nobleza, podían poseer aves y cazar con ellas. Archivo del Reino de Valencia, Justicia Civil, n. 394, mano 3, f. 12 (3-4-1378). 
algún caso se llegara a legislar para asegurar la venta de carne para alimento de las aves durante todo el año, evitando las limitaciones que los diferentes credos (cristiano, judío y musulmán) imponían a la venta de carne para consumo humano. En algunos casos, la caza con aves, además de otras artes, se prohibió completamente debido a los daños ocasionados por los cazadores en sus salidas de caza ${ }^{56}$.

Resulta claro, pues, que la caza con aves en la Edad Media debió ser practicada por gente perteneciente a grupos sociales diferentes, si bien de una forma y con unos objetivos diversos, teniendo siempre presente que debieron darse grandes diferencias a lo largo del tiempo y en los diferentes territorios de la Europa Occidental. No sería exagerado afirmar que prácticamente toda la sociedad medieval estaba familiarizada con la cetrería, ya que se hacía presente en muchos momentos de la vida cotidiana. Los cazadores portaban constantemente sus halcones sobre el puño, no sólo cuando iban de caza, llegando a ir a la iglesia con sus aves, y era habitual que se anunciara públicamente la pérdida de estas preciadas rapaces ofreciendo recompensas a quien las encontrara ${ }^{57}$. También, para alimentarlas, especialmente a las de los grandes señores que las llevaban en sus desplazamientos, los halconeros debían ir comprando palomas y gallinas allí por donde pasaban. Además, un gran número personas y de gentes del lugar debían ser reclutadas para participar como auxiliares en las partidas de caza de los señores. Para los campesinos que trabajaban en sus campos debía ser habitual encontrarse con los cazadores en sus salidas de caza y, a menudo, las aves de los cazadores capturaban, por accidente, las gallinas o las ocas de las aldeas y caseríos ${ }^{58}$. Finalmente, mucha gente sencilla participaba en la búsqueda y vigilancia de nidos para tomar los pollos, aparte de los rederos profesionales dedicados a la captura de aves ${ }^{59}$.

Miembros de algunos oficios artesanales estaban implicados indirectamente en el trato con las aves. Éste era el caso de los boticarios y especieros, que preparaban y despachaban medicinas para los halcones y otras aves de caza, los carniceros, que proporcionaban carne para las mismas, y los carpinteros, que construían y arreglaban las alcándaras. Pero las tripulaciones de las naves y, especialmente los comerciantes, también debieron familiarizarse con estas rapaces y con el vocabulario de la cetrería para poder realizar sus transacciones, ya que transportaban grandes cantidades de halcones de unas tierras a otras ${ }^{60}$.

${ }^{56}$ M.A. Ladero Quesada, La caza en la legislación municipal castellana, pp. 209-213; J.M. Fradejas Rueda, Pasado y presente, pp. 22-24.

${ }^{57}$ Sobre pérdida de halcones, véase J. Bover, R. Rosselló, La falconeria a les Balears, pp. 128132 .

${ }^{58}$ Aunque referido a otra modalidades de caza, hay documentos que prueban la participación de gran número de campesinos del lugar en partidas de caza reales (M.A. Ladero, La casa real en la Baja Edad Media, p. 337) por lo que es posible suponer que también sucediera con la caza con aves. En algunos tratados de cetrería se advierte del problema que supone que las aves se acostumbren a ir a las aldeas a por las aves de corral, por ejemplo, en J.M. Fradejas (ed.), Libro de acetrería y montería, vol. I, p. 154, o en M. Garcia, C. Arronis, H. Càmara (eds.), Libre de animals de caçar, f. 8v.

${ }^{59}$ Sobre las personas encargadas de buscar y capturar los halcones en las Baleares, véase J. Bover, R. Rosselló, La falconeria a les Balears, pp. 80-82. En ámbito castellano, pueden encontrarse referencias en F. de Zúñiga, Libro de cetrería, ff. 3r, 9r y 11 r.

${ }^{60}$ En J. Bover, R. Rosselló, La cetrería en las islas Baleares, pp. 13-15, se encuentra la información relacionada con el transporte marítimo de halcones en las Baleares. Por otra parte, es significativo que en algunos vocabularios temáticos plurilingües que circularon por Europa desde finales del siglo XV, cuyo objetivo era servir de ayuda a comerciantes y viajeros, se incluyeran apartados dedicados a la cetrería, con un gran número de términos específicos. Un estudio sobre el vocabulario cetrero en uno de estos diccionarios, aunque más tardío, puede verse en S. Fornasiero, Struzzeria 'falconeria', pp. 115-128. 
En definitiva, parece difícil imaginar algún rincón de la sociedad que fuera ajeno a esta actividad. Y, efectivamente, un elemento tan común no podía pasar en absoluto desapercibido a los hombres de iglesia, especialmente a los moralizadores profesionales del sermón.

\subsection{La cetrería y la iglesia}

La nobleza eclesiástica participaba de la misma afición a esta modalidad de caza que la nobleza laica. Muchos clérigos no solo practicaban la caza con aves, sino que se contaban entre los mayores expertos, especialmente los obispos, llegando algunos miembros del clero secular y regular a componer tratados sobre la materia ${ }^{61}$. Algunos obispos, al igual que algunos grandes señores, llegaron a tener una desmedida afición por la caza con aves, como Gonzalo de Miguel, obispo de Segovia, a quien su afición le llevó a someter a clérigos y pueblos de su diócesis a vejaciones y tributos desmesurados ${ }^{62}$.

Sin embargo, desde la propia iglesia hubo importantes críticas a la caza con aves. En un intento de evitar que aquellos clérigos que procedían de las filas de la nobleza y formaban parte de la elite social tomaran por norma la ostentación de riqueza y las formas del comportamiento noble y burgués, los concilios y los sínodos prohibieron en reiteradas ocasiones los excesos en la indumentaria, la comida y la bebida o las aficiones poco adecuadas. Este sería el caso de la caza con aves. Ya el concilio de Agde del año 506 prohibió la posesión de perros y aves de caza a los clérigos bajo amenaza de excomunión, lo cual es prueba de lo arraigada que debía estar por entonces esta modalidad cinegética en algunos territorios de la Europa Occidental. Poco efecto debieron surtir estas amenazas para que fuera necesario repetir las prohibiciones en concilios posteriores. Se reconocía entonces que una práctica cara como la caza era incompatible con la humildad que debía ser propia de un prelado ${ }^{63}$. Ahora bien, merece recordarse que las prescripciones conciliares o sinodales iban referidas siempre a la caza con perros y con aves. El franciscano gerundense Francesc Eiximenis nos da la pista de por qué se debía prohibir a los clérigos estas modalidades: ne cans ni aucels retendràs en la casa, car és gran càrrec e poc profit ${ }^{64}$. Efectivamente, mantener estos animales era caro y el único provecho era el de disfrutar en el tiempo de ocio de una afición que para muchos hombres de iglesia, salidos de las filas nobiliarias, debía constituir una actividad irrenunciable que habrían aprendido y practicado en sus casas durante su juventud. La ostentación que hacían en Valencia estos clérigos que llevaban su ave en el puño alardeando de ello, hizo que en el sínodo valenciano de 1298 se les prohibiera tal acción, pero no la caza. Con ello se daba a entender que lo que realmente buscaban era que todo el mundo supiera de su condición especial, de su

\footnotetext{
${ }^{61}$ A finales del siglo XIV, el canciller Pero López de Ayala dedicó su Libro de la caza de las aves a Gonzalo de Mena, obispo de Burgos, reconociéndole como su maestro. Juan I de Aragón tuvo que recurrir al obispo de Valencia, como experto en el arte, para que determinara qué tipo de halcón era un ave que había recibido y que él mismo, también experto, había sido incapaz de identificar. Matías Mercader, arcediano de la catedral de Valencia escribió a finales de siglo XV su Pratica de citreria breve para el rey Fernando (Pratica de citreria breve, Matías Mercader, Biblioteca Nacional, Ms. Res/179).

62 J.M. Fradejas, Pasado y presente, p. 24. Para información detallada sobre la relación entre la cetrería y la iglesia, en ámbito inglés, véase R.S. Oggins, The kings and their hawks, pp. $120-126$.

${ }^{63}$ T. Szabó, Die Kritik der Jagd, pp. 177-189. También en G. Oppitz-Trotman, Birds, beasts and Becket, pp. 78-88, especialmente p. 83.

${ }^{64}$ R.J. Puchades, Als ulls de Déu, als ulls dels homes, p. 178.
} 
origen noble y su capacidad de cazar con aves $\operatorname{caras}^{65}$. Sin embargo, no parece que se tomaran medidas coercitivas para limitar estas actividades cinegéticas ni la posesión de aves por parte de los clérigos. De hecho, los mismos obispos no pudieron resistirse a continuar cuidando sus propias aves, y tenemos ejemplos que lo corroboran ${ }^{66}$. Resulta de gran interés, además, el constatar que tanto el obispo de Valencia como el de Barcelona, y también el paborde de Tarragona, disponían de sus propios agres en las islas Baleares, de donde reclamaban anualmente los pollos a sus respectivos procuradores ${ }^{67}$. Estas noticias nos indican que las autoridades eclesiásticas, como ocurriera en otros temas, hicieron caso omiso de las advertencias que ellas mismas se habían dado con anterioridad.

Más allá del interés de los clérigos por poseer aves y cazar con ellas, podemos constatar la atención que los religiosos interesados por la filosofía natural dedicaron a la cetrería, como una expresión más de la naturaleza a la que la ciencia puede aproximarse. Así, el dominico Alberto Magno, en el apartado correspondiente al halcón de su obra De animalibus, se extendió introduciendo en dicho apartado un completo tratado de cetrería. Del mismo modo, el franciscano Juan Gil de Zamora, en la entrada De accipitre de su Historia naturalis, se detuvo en tratar la caza con el azor, su adiestramiento y la cura de sus enfermedades ${ }^{68}$.

\subsection{La simbología asociada al ave de caza y al cazador}

Esta actitud tan contradictoria en el seno de la iglesia hacia la caza con aves, con muchos practicantes entre sus filas, junto a reiteradas condenas y penas de excomunión, encuentra un reflejo en la simbología asociada a las aves de cetrería y a la práctica de esta modalidad de caza en la Baja Edad Media. El análisis de la iconografía en la que aparece un halcón sobre el puño de su dueño refleja claramente esta ambivalencia simbólica. Son numerosos los contextos en los que dicha imagen aparece asociada a las ideas de nobleza, paz y concordia, amor, primavera o juventud, todas ellas de carácter positivo. Frente a estas imágenes, muchas otras aparecen representando aspectos negativos y censurables de la naturaleza humana, especialmente las vanidades mundanas y algunos vicios concretos, como el orgullo, la soberbia, el odio o la envidia. El hecho de no aparecer el ave de caza en la Biblia ni en el Physiologus, base de la simbología animal cristiana, ha sido propuesto como explicación de esta polivalencia o falta de especificidad simbólica ${ }^{69}$.

65 Para el caso valenciano, también con la alusión a una prohibición sinodal, véase ibidem, pp. 177-178.

${ }^{66}$ Así, el obispo de Valencia hizo donación de un gerifalte al rey Juan I. También, el 5 de mayo de 1375 , se dio permiso al obispo de Barcelona para que "possit abstrahere a regno Maioricarum decem falconos muntarinos quos habuit de parrochia Andragii de agriis qui ibi sunt", y en diciembre de 1394 el obispo de Mallorca perdió un "falcó mudat senyat de foch ab los gits de senyal de mossèn lo Bisbe de Mallorques", lo que demuestra el celo con el que se conservaban estos animales. J. Bover, R. Rosselló, La falconeria a les Balears, pp. 89, 206 y 209.

${ }^{67}$ Los agres eran los nidos o lugares de nidificación de los halcones, de donde anualmente se tomaban los pollos. También una institución eclesiástica de la relevancia de la orden de San Juan de Jerusalén poseía sus agres en Mallorca. Véase J. Bover, R. Rosselló, La falconeria a les Balears, pp. 75-78.

${ }^{68}$ H. Stadler (ed.), A. Magnus, De animalibus libri XXVI, vol. II, pp. 1453-1493; A. Domínguez, L. García (eds.), J. Aegidii, Historia naturalis, vol. I, pp. 180-227.

${ }^{69}$ B. Van den Abeele, Le faucon sur la main, pp. 95 y ss.; R.S. Oggins, The kings and their hawks, pp. 135-138. Esta ambigüedad potencial del ave o del cazador fue aprovechada en la literatura religiosa de la época y, por ejemplo, resultó especialmente atractiva para los biógrafos y recopiladores 
Algunos teólogos representaron al mal clérigo con un halcón en el puño, recordando que la halconería era una afición de gente ociosa y vanidosa, e incluso se la asoció con la lujuria. Sin embargo, en otras ocasiones, el monje, hombre santo, es comparado, en su actitud contemplativa, al halcón que descansa en la alcándara. También la vida monástica fue comparada con el vuelo alto y remoto del halcón. En definitiva, al halcón le fue dado también un significado místico ${ }^{70}$. Con un sentido próximo, al esfuerzo necesario para adiestrar un ave de presa se le ha hecho corresponder con la lucha interior por la autosuperación, basándose en las exigentes cualidades personales que se requieren para poder adiestrar adecuadamente un halcón ${ }^{71}$. Otra interpretación mística del ave estaría asociada a la conversión. La izquierda representa lo temporal, la derecha lo eterno. En este contexto, el vuelo del halcón, que parte de la mano izquierda del cazador y vuela hacia la derecha a por su presa, simboliza la persecución de lo eterno, la gracia del Espíritu Santo. Por ello, un halcón asociado a un santo representa, a menudo, un origen noble o una vida mundana antes de la conversión ${ }^{72}$.

Sin embargo, el testimonio más interesante, en este sentido, nos lo proporciona el décimo capítulo de la entrada De accipitre de la enciclopedia del fraile franciscano Juan Gil de Zamora, Historia naturalis. En él se expresa con todo detalle, por qué está justificada la comparación de san Francisco, creador de la orden, con el azor $^{73}$. La muda natural del azor, que lo renueva, es comparada con la transformación de san Francisco en un serafín. También el azor quita la comida a sus hijos para obligarles a abandonar el nido, del mismo modo que san Francisco fue severo con sus hermanos al establecer una orden estricta. Al igual que el azor cura los ojos de sus hijos con su propia hiel ${ }^{74}$, el padre fue una medicina para sus hermanos a través de su santa profesión. El azor ataca a las presas, igual que san Francisco convertía a otros hombres con la predicación. Y, del mismo modo que el azor gusta de la carne fresca y ensangrentada, el fundador de la orden meditaba frecuentemente sobre la pasión del Señor ${ }^{75}$. En este testimonio, cada una de las cuatro direcciones en las que extiende las alas el azor -hacia arriba, hacia abajo, hacia la derecha y hacia la izquierda- recibe una interpretación, a saber, desear la recompensa de los bienaventurados, no olvidar los suplicios de los condenados, imitar la rectitud de la vida de los santos y evitar las consecuencias de los pecados, respectivamente ${ }^{76}$.

El interés de este testimonio es doble. Por una parte, como veremos, la obra de Juan Gil de Zamora podría haber sido una fuente, directa o indirecta, de Vicente Ferrer. Por otra parte, la actitud que se vislumbra en el fraile valenciano hacia las aves de caza, ciertamente ambigua, podría estar influida, en su vertiente positiva, por

de los milagros de Thomas Becket, apasionado cazador en su juventud. G. Oppitz-Trotman, Birds, beasts and Becket, p. 78.

${ }^{70}$ G. Oppitz-Trotman, Birds, beasts and Becket, pp. 81-82.

${ }^{71}$ Estas cualidades necesarias para el adiestramiento fueron puestas de manifiesto en varios tratados de cetrería, como el de Adelardo de Bath. Véase ibidem, p. 80. También Federico II menciona las cualidades personales que debe poseer el halconero. Véase nota 40.

${ }^{72}$ R.S. Oggins, The kings and their hawks, pp. 81-82 y 133.

73 "Accipitri beatus Francisco merito comparatur". A. Domínguez, L. García (eds.), Historia naturalis, p. 216.

${ }^{74}$ La hiel del azor y de otras aves de presa fue considerada en la Edad Media un eficaz remedio para algunas enfermedades de los ojos. Véase, por ejemplo, J. Cull, B. Dutton (eds.), Un manual básico de medicina medieval, p. 139.

75 A. Domínguez, L. García (eds.), Historia naturalis, p. 218.

${ }^{76}$ Ibidem, p. 220. 
la obra del franciscano. Y es que, curiosamente, alguien como fray Vicente Ferrer, tan contrario a las vanidades mundanas, criticó en diversas ocasiones la posesión de caballos ataviados con arreos preciosistas y el coste de su mantenimiento, pero nunca criticó la posesión de halcones ${ }^{77}$. Parece que nuestro predicador también conservó cierto interés hacia estas preciosas aves aunque, seguramente, no llegara a ser un cazador como otros hombres de la iglesia.

\section{LA CETRERÍA EN LOS SERMONES VICENTINOS}

Al revisar detenidamente los sermones y sermonarios de Vicente Ferrer en busca de referencias a la caza, lo primero que llama la atención es la presencia casi exclusiva de la cetrería y de las aves empleadas en esta técnica venatoria. De hecho, otras modalidades cinegéticas están mucho menos representadas en sus sermones, tanto aquellas que podían gozar de gran prestigio social, por estar reservadas a nobles y grandes señores (montería), como aquellas otras de rango inferior, pero más accesibles a una mayor parte de la sociedad bajomedieval (perros, trampas). Quizá esta modalidad de caza ofrecía, por sí misma, elementos más adecuados para construir las analogías que facilitarían la comprensión del mensaje que pretendía transmitir el predicador. Sin embargo, nos parece que tal vez otras razones podrían explicar esta preferencia de Ferrer, más relacionadas con su propia experiencia y con la realidad de la sociedad a la que se dirige.

Las referencias a las aves y a la cetrería que encontramos en los sermones de Vicente Ferrer nos llevan a pensar que el predicador debía conocer de primera mano los diferentes aspectos relacionados con la cetrería (las aves, su adiestramiento, la caza, etc.), por lo que no debía resultarle difícil recurrir a algo por él conocido para hacer más comprensible a su auditorio los oscuros y complejos conceptos teológicos. Este hecho puede justificar, en parte, el uso de este motivo en sus sermones. Sin embargo, parece razonable pensar que si fray Vicente explicaba los contenidos teológicos o sus ejemplos morales, con ejemplos procedentes del campo de la cetrería, es porque entendía que éstos últimos serían fácilmente comprensibles para sus oyentes, lo que apoyaría la descripción anteriormente hecha de una sociedad muy familiarizada con las aves de caza.

En los sermones de Vicente Ferrer, halcones y gavilanes, además de los cazadores y las presas, son protagonistas en un significativo número de ejemplos o de símiles. Al igual que en otros casos, también aquí el predicador acudió a fuentes escritas, especialmente cuando lo que se aprovechaba era alguna "propiedad" del animal, recurso ampliamente empleado por los predicadores medievales. En uno de sus sermones se refirió a la transformación que provoca la muda del azor: accipiter expandens alas suas ad austrum renovatur ${ }^{78}$. Pese a la brevedad del texto, no es difícil encontrar este pasaje en las diferentes enciclopedias medievales, como en la

77 Se trata de un comentario a 1 Cor 12, 10: "Per spiritum datur operacio virtutum" (J. Perarnau, Aportació, § 649, p. 713), en la cual se predica sobre las virtudes morales. Concretamente, en este caso, sobre la tercera: la templanza corporal. Vicent Ferrer, Sermons, vol. III, p. 60. En un comentario a Lucas 8, 5 ("Exiit qui seminat, seminare semen suum"), se refiere al predicador y a quiénes se dirigen sus palabras. Éste debe predicar contra la avaricia y la usura, y prevenir de pensamientos vanos, como es el caso del mantenimiento del caballo. Vicent Ferrer, Sermons, vol. V, p. 86 (J. Perarnau, Aportació, § 314, p. 591).

${ }^{78}$ El tema pertenece a Eph 4, 23: "Renovamini spiritu mentis vestre" (J. Perarnau, Aportació, § 743, pp. 748-749). Vicent Ferrer, Sermonario de Perugia, p. 433. En el sermón, Ferrer pone ejemplos de diversos animales que se renuevan de formas diversas (águila, ciervo, serpiente). 
de Juan Gil de Zamora: Per sapienciam tuam, Deus, plumescit accipiter expandens alas suas ad Austrum ${ }^{79}$. En otro sermón, para explicar las virtudes del ayuno recurrió a la ligereza de carnes de las aves de caza, que les permite elevarse en el cielo: $A d$ oculum enim videmus, quod aves que habent multas carnes et modicas plumas, non possunt multum volare, et econtra, que habent multas plumas et modicas carnes, volant multum et alcius ${ }^{80}$. También en este caso podemos encontrar una relación con el texto del franciscano: Struccioni autem est immane corpus et rare penne. E contrario autem herodio et accipitri, qui et aves reliquias trascendunt velocitate ${ }^{81}$. Estos usos del motivo estarían en consonancia con la significación mística atribuida a las aves de caza vista anteriormente y asignan al ave un valor positivo. Y, aunque no coincide exactamente con la interpretación mística del vuelo del halcón de la izquierda hacia la derecha, quizá pudiera rastrearse alguna reminiscencia o influencia de dicho significado en otro sermón:

sicut falco cum una ala, vel sinistra, vel dextera, non potest volare, licet se svolatige, ita qui habet unam solam alam, vel dexteram, scilicet veram credenciam ut mali christiani, vel sinistram, ut sarraceni bonam vitam gerentes, non poterunt volare ad gloriam ${ }^{82}$.

Sin embargo, a medida que san Vicente deja de recurrir a las "propiedades" de las aves y se aproxima al motivo de la caza o a la relación entre las aves y el cazador, el predicador se aleja de las fuentes escritas. Así, en uno de sus sermones castellanos se dibuja una detallada escena de caza:

el periglo en que están nuestras ánimas quando deven salyr de la carne. Buena gente, el periglo en que está la ánima del omne o de la mugier en aquel estado es así como si estodiesse una perdiz metida en una mata e estodiessen más de çient falcones en el ayre aguardando la perdiz; e estodiessen otros çient podencos perdigueros que andodiesen enderredor de la mata aguardando la perdiz quando saliesse para tomarla; e estodiessen fasta XX omnes con palos para la fazer salir. E cata que la perdiz non puede quedar en la mata, ca le es forçado de salyr aunque non quiera. $\mathrm{O}$, captiva de perdiz, ¿si avría algún rremedio para escapar? Non ay sinon uno; e éste es que estoviesse un omne çerca de la mata e ella saliesse e el omne la tomasse e la librasse de los perros e de los falcones e de los omnes e después la soltasse ${ }^{83}$.

En este fragmento, Ferrer comparaba el alma cuando abandona el cuerpo -la mata que le sirve de refugio- con la perdiz acechada por los perros y los halcones, que son los demonios que aguardan para tomarla, mientras es hurgada y batida por los dolores.

${ }^{79}$ A. Domínguez, L. García (eds.), Historia naturalis, vol. I, p. 216. El pasaje, que procede de la Biblia (Job 39, 26), fue incorporado a las "propiedades" del azor (accipiter) en varias enciclopedias, como la de Tomás de Cantimpré o la de Bartolomé el Inglés.

${ }^{80}$ Comentario a Mateo 4, 11: "Ecce angeli accesserunt [AA: accesserunt angeli], et ministraban ei” (J. Perarnau, Aportació § 201, p. 553). Vicente Ferrer, Colección de Sermones de Cuaresma y otros según el Manuscrito de Ayora, p. 50.

${ }^{81}$ A. Domínguez, L. García (eds.), Historia naturalis, vol. I, p. 184; se compara el avestruz con el halcón gerifalte y el azor.

${ }^{82}$ Mateo 28, 18: "Data es mihi potestas in caelo et in terra" (J. Perarnau, Aportació, § 142, p. 534). Vicente Ferrer, Sermonario de San Vicente Ferrer, p. 158.

${ }^{83}$ Lucas 19, 41: "Videns (Ihesus) civitatem flevit super illam" (J. Perarnau, Aportació, § 880, p. 793). P.M. Cátedra, Sermón, sociedad y literatura, p. 472. 
Solamente los ángeles podrán salvar el alma de todos estos peligros. Y fue en el momento en que el alma abandonó a Jesucristo cuando éste lloró de compasión por quinta vez.

Lo importante de este pasaje es que todos los elementos relacionados con la cetrería corresponden exactamente a lo que, según nuestros conocimientos actuales de la cinegética medieval, debía ser el desarrollo de una partida de caza. Efectivamente, en la técnica conocida como altanería, el halcón (o los halcones, ya que podían emplearse varios simultáneamente) espera a gran altura en el cielo sobrevolando el lugar donde se oculta una presa, que deberá ser forzada por perros y hombres con palos a abandonar su refugio, momento en el que el halcón se abatirá sobre ella asestándole un golpe mortal. En caso de que la presa se resistiera a abandonar el refugio, sería atrapada por los perros.

$\mathrm{Ni}$ en las obras que sabemos conocidas por nuestro predicador, ni en los tratados de caza se encuentra una descripción que podamos considerar una fuente directa para este sermón. Tan solo en la obra de Pedro Berchorio, benedictino del siglo XIV, encontramos un pasaje en el que se hace referencia a la amenaza de las aves de presa:

Ista est enim cautela columbae, quia inter accipitres praedantes in aere et paredantes in terra discernit. Unde si videt accipitrem qui praedatur in aere sursum, statim ad terram descendit, et loca bassa et humilia quaerit, et a rapina accipitris sic evadit, sicut dicit super cantica. Sic vere homo qui videt quod accipiter .i. diabolus non cessat sursum in aere .i. in statu dignitatum et officiorum per diversa tentamenta peccatorum rapere ${ }^{84}$.

Aunque ambos pasajes coinciden en la representación de la amenaza mediante las aves de presa, ni el mensaje religioso que transmiten, ni los elementos de la narración concuerdan, por lo que, si Vicente Ferrer pudo inspirarse para su sermón en este o en otro texto similar, necesariamente tuvo que recurrir a otras fuentes para introducir todos los detalles de la narración que, como hemos visto, corresponde a una escena verosímil de caza. No parece, por ello, aventurado suponer que, en esta ocasión, Vicente Ferrer describe una escena presenciada por él y, seguramente, familiar a muchos de sus oyentes ${ }^{85}$.

Este símil puede, además, ayudarnos a entender la forma en que Vicente Ferrer construía sus narraciones. En otro sermón, para transmitir el mismo mensaje, recurre a otra modalidad de caza, sustituyendo todos los elementos necesarios para que la escena descrita se ajuste al nuevo escenario y siga siendo verosímil y, por lo tanto, reconocible y familiar a sus oyentes:

Pensad que es assí como ssi aquí estoviese una mata de yerva e estodiese dentro della ascondido un conejo, e estodiessen enderredor de la mata mill galgos e muchos omes con palos furgando la mata por que saliesse della. ¿O, mesquino de conejo, qué faría? ¡Buena gente, pensad si este conejo está en tribulación! Assí digo que la ánima peccadora que está en la carne, que es la mata, está en mucha tribulaçión, ca vee estar enderredor de ssí mill millares de diablos ${ }^{86}$.

${ }^{84}$ P. Bersuire, Dictionarii seu repertorii, p. 288.

${ }^{85}$ En una obra de cetrería bastante posterior (1556) encontramos un pasaje que permite comprobar la verosimilitud de la imagen presentada por san Vicente: "y el halcón sube arriba y anda siempre alto y redondo esperando que le levanten la perdiz, y assí como sale la perdiz, cae el halcón a ella (...) y vanse muy pocas perdizes de la vanda porque, como el halcón anda en lo alto, no osan levantarse y las más dellas matan los perros". J. Vallés, Libro de acetrería y montería, J.M. Fradejas (ed.), vol. I, p. 147.

${ }^{86}$ Lucas 19, 47: "Erat qotidie docens in tenplo" (J. Perarnau, Aportacions, § 276, p. 579). P.M. Cátedra, Sermón, sociedad y literatura, p. 330. 
Parece que, al menos en ciertos casos, más que recurrir a algunos de los muchos exempla de las recopilaciones que estaban disponibles para los predicadores, o de las "propiedades" de algunos animales, recogidas en las enciclopedias, Vicente Ferrer partía de un motivo, quizá inspirado a partir de un texto, y construía su ejemplo introduciendo los elementos necesarios, posiblemente a partir de su experiencia, para dibujar una escena familiar y comprensible a su auditorio.

También del cuidado de las aves parece el predicador conocer algunos detalles, pues en otros sermones, pese a basarse sin duda en fuentes escritas conocidas, introdujo elementos nuevos que, al igual que en el caso anterior, son perfectamente verosímiles, pese a la apariencia de ser invenciones arbitrarias para adornar la narración. En el siguiente pasaje, utilizado por Ferrer para destacar cómo será retribuido el cristiano por Dios después de la muerte,

Lo rich e lo pobre són axí com lo falchó e la gallina: lo falchó, ja sabets com lo senyor lo porta en la sua mà, e al vespre lo falchó, pus alt dorm que lo senyor, e en lo estiu ell lo refrescha, en lo yvern en la sua cambra lo met; tan gran servir li fa ab grans maravelles; e la gallina gitar-l'an de la cambra e de taula. Emperò com la gallina és morta, ve davant lo senyor a taula, e, lo falchó mort, diu: 'Gitats-lo al femer'. Axí és açò: lo rich faç servir altament, e com ve lo rich hom, tot hom lo acull e lavar los peus al rich; lo pobre viu pobrament, e en lit ple de xinxes: mor lo pobre, que no gosava comparer davant los richs, axí com la gallina. Axí, vejats com se muda ${ }^{87}$.

podemos fácilmente reconocer una estrecha relación con un fragmento de la Historia naturalis de Gil de Zamora:

Accipitres, quandiu vivunt et potentes sunt ad predandum, a suis dominis diliguntur et in manibus gestantur et super perticam reponuntur. In pectore et in cauda manibus complanantur et cum diligencia nutriuntur. Sed quando moriuntur, ab omnibus inutiles reputantur, non enim comeduntur; sed pocius super sterquillinum prohiciuntur ${ }^{88}$.

Esta "propiedad" del azor ya había sido empleada con anterioridad a Vicente Ferrer en Renart le Contrefait, obra de un clérigo en la que, mediante comparaciones, criticaba la sociedad de su tiempo y sus vicios. En la versión francesa, sin duda relacionada con la de Vicente Ferrer, ya se introduce el otro elemento, el capón (la gallina, en el predicador), junto con una lección moral. Además, las ampliaciones que contiene permiten vislumbrar un autor con importantes conocimientos sobre la cetrería, incluso, en palabras de Van den Abeele, fascinado por ella ${ }^{89}$. Es difícil concluir si Vicente Ferrer tuvo o no esta obra como fuente directa, lo que es cierto es que algunas de las adiciones del predicador valenciano no se encuentran en el texto francés y, al igual que en el caso del clérigo, los elementos añadidos no son en absoluto arbitrarios. Tanto el hecho de que el cazador porte el halcón a su cámara y duerma en una alcán-

${ }^{87}$ Lucas 16, 29: "Habent Moysen et proffetas: audiant illos" (J. Perarnau, Aportacions, § 375, p. 614). J. Sanchis Sivera, Quaresma de Sant Vicent, p. 112.

${ }^{8}$ A. Domínguez, L. García (eds.), Historia naturalis, vol. I, p. 216. El texto es prácticamente idéntico al de Bartolomé el Inglés, que debió de ser la fuente de Juan Gil. Puede verse en B. Van den Abeele, La fauconnerie dans les lettres françaises, p. 209, nota 210.

${ }^{89}$ Ibidem, pp. 207-208. El fragmento que contiene el pasaje al que se ha hecho referencia puede leerse en la misma obra, p. 313. 
dara alta, como la práctica de proporcionar el baño a las aves se encuentran perfectamente documentados en los tratados de cetrería y en las fuentes iconográficas ${ }^{90}$, lo que nos lleva a suponer en Vicente Ferrer una actitud hacia las aves de caza similar a la del autor de Renart le Contrefait.

Al contrario de lo que sucedía en los primeros sermones analizados, en estos últimos el halcón es portador de un significado negativo. En un caso, halcones, perros y hombres representan el mal que acecha a las almas de los hombres y mujeres. En el otro sermón, el halcón representa al rico y a la buena vida terrenal que de nada sirve cuando llega la muerte. Con ello podemos ya constatar que Ferrer no atribuía un valor simbólico fijo al ave de caza, sino que lo cambiaba según las necesidades de sus sermones, en consonancia con la polivalencia simbólica que tenían estos animales en la Edad Media. Quizá donde mejor se observa este uso inespecífico es en un motivo que aparece repetido en numerosos sermones, en el que la misma ave, en dos estados diferentes, representa al cristiano bueno (humilde, pobre) y al malo (rico).

En uno de estos sermones leemos:

la diferència que és entre lo falcó sadoll e lo qui és mort de fam; que lo senyor lo cride: 'Hu hoo!', tantost ve; mas, si és sadoll, 'Ara iré', cabotege, e no·s mou. ¿E què fa lo senyor? Pren lo bastó, e mate'l, e lance'l al femer. Tal diferència hi ha entre lo pobre e lo rich ${ }^{91}$.

El rico (representado por el ave cuando está saciada), interesado solo por la buena vida terrenal, no atiende a la llamada de Dios y por ello es castigado, mientras que el pobre, que acude presto (representado por el ave hambrienta), recibe su recompensa. Incluso el papel simbólico del cazador es muy significativo, pues representa al Todopoderoso, que imparte justicia.

Se trata de un símil construido a partir de motivos que ya estaban en circulación antes de nuestro predicador. Por una parte, la comparación que se establece entre el señuelo, armadijo de cuero en el que se ata la carne para llamar al halcón, y la cruz con el cuerpo ensangrentado de Jesucristo, para llamar a los cristianos. Así, Esteban de Borbón, dominico del siglo XIII, escribe: Passio Domini et crux eius a malo revocat; unde sit reclamatorium, ubi caro rubea ligno crucis colligatur, ad revocandum aves venatorias que a manu nobili avolaverunt ${ }^{92}$. Y, en el segundo motivo, se compara a las aves de cetrería saciadas, que no acuden a la llamada de su dueño, con los hombres que disfrutan de las riquezas mundanas. Por ejemplo, en Pedro Berchorio, encontramos:

Anima saturata calcabit favum, esuriens autem etiam amarum pro dulci sumet. Isti sunt similes falconi, qui quando habet guttur plenum abominatur venire ad reclamatorium magistri sui, immo circumquaque volat et fugit, ita quod aliquando perditur. Sic vero tales qui pleni sunt mundi

\footnotetext{
${ }^{90}$ Pueden encontrarse referencias, por ejemplo, en M. Delgado, Edición crítica del Libro de la caza de las aves, pp. 203 y 168. Véanse también la miniatura y el fresco reproducidos en J.M. Fradejas, Pasado y presente, pp. 88 y 89.

${ }^{91}$ Lucas 14, 21: "Pauperes ac debiles et caecos et claudos introduc huc" (J. Perarnau, Aportació $\S 642$, p. 710). Vicent Ferrer, Sermons, vol. II, p. 43. Esta misma analogía aparece, con pequeñas variantes, en varios sermones, tanto en catalán como en latín. En cualquier caso, las pequeñas variantes que aparecen, como en todos los sermones que recurren a la cetrería y a las aves, no son arbitrarias. Vicente Ferrer, Sermonario de San Vicente Ferrer, pp. 732, 324 y 619.

${ }^{92}$ A. Lecoy de la Marche, Anecdotes Historiques, pp. 85-86.
} 
divitiis et delitiis parum pro certo reputant reclamationem Christi, et suorum praedicatorum, immo ipsum fugiunt et abominantur ${ }^{93}$.

Estos dos motivos, que a veces aparecen de forma independiente, a veces asociados, parecen estar en la base del ejemplo de Vicente Ferrer. Sin embargo, las modificaciones y ampliaciones que introdujo el predicador, por insignificantes que pudieran parecer, son las que dan forma a una escena verosímil que bien pudo presenciar el fraile valenciano. En efecto, una situación muy común en el transcurso de una salida de caza o durante el adiestramiento del ave era que el cazador tuviera que llamarla para recuperarla después de un vuelo. Como sabemos, el único modo de que el ave acuda a la llamada es mostrándole el alimento para que ésta, por hambre, se acerque a comer ${ }^{94}$. La situación descrita por el predicador debía darse con mucha frecuencia, debido a que no todos tenían la pericia necesaria para adiestrar y manejar adecuadamente al ave y ya en los diversos tratados medievales de cetrería se dan instrucciones para resolver esta situación ${ }^{95}$. Incluso el desenlace que describía Vicente Ferrer en estos casos, en el que el cazador mata al ave que no acude a su llamada, y que tan útil le resultaba para explicar el castigo que reciben los que no siguen a Dios, parece una situación verosímil a la luz de las informaciones que nos proporcionan algunos tratados de caza ${ }^{96}$.

Sin embargo, los detalles que parecen más insignificantes son los que nos permiten pensar que la escena descrita corresponde a una situación presenciada por el predicador y fácilmente reconocible y comprensible por su auditorio. Proferir gritos para acompañar la llamada del ave, Hu hoo, debía ser habitual, a juzgar por las instrucciones que sobre ello se encuentran dispersas por los diferentes tratados de caza e incluso por las huellas que quedaron en la literatura castellana ${ }^{97}$. Algunos de estos detalles parecen insignificantes, inventados para adornar o adecuar el sermón y su interés reside, precisamente, en la perfecta adecuación a la realidad. Así, el gesto que hacen los halcones cuando fijan la vista, como asintiendo, que fray Vicente expresaba de diferentes modos (cabotege; licet nutu capitis videatur assentire; ipse facit cum capite inclinando), parece más una descripción de algo observado que tomado de alguna fuente escrita. Posiblemente, cualquier cazador medieval podía reconocer e interpretar perfectamente estos y otros muchos gestos de sus aves por haberlos presenciado y

${ }_{93}$ P. Bersuire, Dictionarii seu repertorii, p. 14.

${ }_{94}$ Aunque en este caso no se menciona la carne, en otros sermones dice explícitamente que se le muestra al ave la carne en el puño. Véase, más adelante y nota 101.

${ }_{95}$ Por ejemplo, en el Libre de animals de caçar leemos: "Si vostre astor o sparver cridant-lo o lançant-lo a qualque presa se stava en qualque arbre o altre loch que no.l poguessets alcançar ab la mà per pendre-lo e-l cridau al puny e no vol venir (...) sperats-lo tant e tant per gran enuig que us sia, tro que ell vinga al puny. E, quant de tot en tot veurets que no vol venir", en M. Garcia, C. Arronis, H. Càmara (eds.), Libre de animals de caçar, f. $8 \mathrm{v}$.

${ }^{96}$ Aunque no hemos encontrado una mención explícita al hecho de que el cazador mate a su ave, sí es frecuente encontrar alusiones al enfado e irritación que provocan en el halconero algunos comportamientos de sus aves, como cuando no acuden a la llamada. Federico II, previniendo las consecuencias que puede tener este estado de ira, advierte que el halconero "Non sit iracundus neque facilis ad iram. Accidit persepe enim, quod avis facit ea, per que ille, qui custodit eam, ad iracundiam provocatur, et nisi illam iracundiam dimittat, malo motu moveri poterit contra avem, ex quo malo illato avi per iram avis ipsa, cum sit debilis res, citissime devastatur". A.L. Trombetti (ed.), De arte venandi cum avibus, p. 354.

${ }_{97}$ Puede verse la explicación de Juan Manuel en J.M. Fradejas, Don Juan Manuel y "El libro de la caza”, p. 151. Por otra parte, la voz Huchohó aparece en la literatura como específica para llamar a los azores, aves muy similares a los gavilanes salvo por su tamaño. Véase V. García, Voces a los animales, p. 299. 
observado en infinidad de ocasiones, aunque evidentemente no han quedado recogidos en los tratados de cetrería, ya que ello habría llevado a una prolijidad excesiva e innecesaria. No obstante, la precisión y meticulosidad del emperador Federico II nos brinda una muestra excelente de que estos detalles no pasaban desapercibidos a los cazadores ${ }^{98}$. Exactamente lo mismo sucede cuando el dominico comparaba la mirada del ave de presa con la de un ladrón, al captar la forma habitual de los halcones de mirar, como de soslayo, cuando divisan otro animal en el cielo, contrariamente a la de la paloma, semejante a la mirada de la Virgen María:

Et dicit: 'occuli columparum', nam diferencia est inter oculos columbe et gavilanis, nam gavilal habet oculum rapine, respiciendo versus celum indirecte sive ex transverso, si haberet avem volantem ut eam recipiat; sic est in mala muliere vel homine qui volunt rapere, etc. Sed columba respicit versus terram, ita virgo Maria ${ }^{99}$.

Dos son las aves que el predicador empleaba cuando recurría en sus sermones a la cetrería: el gavilán y el halcón. Si bien es cierto que los cazadores medievales distinguían y empleaban un número mucho mayor de aves, Ferrer parece huir del vocabulario técnico del arte y, en concreto, de los numerosos nombres de las aves, seguramente en un intento de limitar su discurso a los términos y conceptos más conocidos por sus oyentes. Sin embargo, esto no significa que el predicador empleara arbitrariamente en sus sermones una u otra ave, que tan diferentes características tienen en su empleo como auxiliares de caza. Cuando en sus sermones quiso transmitir a su auditorio la imagen de algo muy lejano, recurrió a la capacidad de vuelo del halcón (y nunca del gavilán) y a la distancia que podría éste recorrer volando sin cesar durante miles de años: e per ço com tu estàs lluny d'ell quant ha d'ací fins el cel, més que hun falcó no porie anar en $\cdot X m \cdot$ anys entre nit e dia, si tanta força havie e tant podia viure $^{100}$. En cambio, cuando proporcionó algún detalle de cómo el cazador llama a su ave, tampoco confundió que halcones y gavilanes eran llamados de forma diferente: et iam mulieres volant cum maritis, sicut avis gavilán ad pugnum, ad bonam vitam, docendo eis carnem rubeam, sicut gavilano ${ }^{101}$. Esto es especialmente significativo si tenemos en cuenta que, como hemos visto, una de las probables fuentes para este símil hace referencia explícita al señuelo (reclamatorium) que se empleaba para llamar

${ }^{98}$ Federico II explica cómo ciertos movimientos de la cabeza son señales por las que el cazador puede reconocer que el halcón no responderá a la llamada, en este caso mediante el señuelo: "De signis que faciunt falcones non diligentes loyrum. (...) Et [si] ille qui portat falconem, ostendit loyrantem falconi, falco ipse quandoque respicit ad loyrum, quandoque ad aliam partem, nunc dextrorsum, nunc sinistrorsum. Et cum aspiciet ad loyrum, movebit caput et collum versus loyrum" en A.L. Trombetti (ed.), De arte venandi cum avibus, p. 622.

${ }^{99}$ Mateo 1, 18: "Inventa est in utero habens [de Spiritu Sancto]" (J. Perarnau, Aportació, § 464, pp. 644-645). Vicente Ferrer, Sermonario de San Vicente Ferrer, p. 619. También en este caso la perspicacia de Federico II nos ayuda a comprender que se trata de un gesto reconocido por los halconeros medievales: "Signa que facit falco priusquam iactatus sit, propter aves, quas timet, videndo eas circumvolantes alte vel transeuntes a longe (...) Comovet etiam caudam et aspicit firmius quando uno oculo, quando alio". A.L. Trombetti (ed.), De arte venandi cum avibus, p. 1022.

${ }^{100}$ Lucas 14, 16: "Fecit caenam magnam et vocavit multos" (J. Perarnau, Aportació, § 342, p. 601). Vicent Ferrer, Sermons, vol. II, p. 77.

${ }^{101}$ Mateo 2, 1: "Ab Oriente venerunt Hierosolymam" (J. Perarnau, Aportació, § 2, p. 481). Vicente Ferrer, Sermonario de San Vicente Ferrer, p. 732. Las aves eran llamadas mostrándoles un trozo de carne. Sin embargo, a azores y gavilanes se les mostraba el alimento directamente con la mano enguantada, mientras que a la mayor parte de los halcones se les llamaba con el ya mencionado señuelo (reclamatorium, en latín), que se comparó con la cruz de Cristo. 
a los halcones pero no a los gavilanes, permitiéndonos comprender la sutileza de la construcción de sus sermones.

Es de destacar también que, a diferencia de lo que sucede cuando el predicador construía su sermón ciñéndose a una fuente escrita, en cuyo caso empleaba el término latino para referirse al ave (accipiter expandens alas suas ad austrum renovatur), cuando parece describir una situación más relacionada con su experiencia y la de su auditorio, Vicente Ferrer intercalaba, en el texto latino, los términos vernáculos correspondientes y las aves eran, a menudo, nombradas en catalán o castellano: sicut avis gavilán ad pugnum; sicut al falcó farto qui; diferencia est inter oculos columbe et gavilanis ${ }^{102}$.

Además, a través de los sermones vicentinos podemos constatar que, en aquella sociedad, la capacidad para cazar no era el único aspecto que interesaba de las aves de cetrería. Dijo el predicador en un sermón referido a cómo debe el hombre amar a Dios sobre todas las cosas, y concretamente refiriéndose a la bondad: E non solamente ama un omne a otro por ser bueno, mas aun ama omne un buen cavallo o un buen falcón para caçar o aun un buen capón para comer. Y, más adelante: Esso mismo ama omne un falcón por ser fermoso, o otra ave fermosa. Con ello nos deja constancia de la percepción que la sociedad tenía de las aves de caza ${ }^{103}$.

Para concluir este análisis de los sermones vicentinos, queremos mostrar un punto más de correspondencia entre las palabras del predicador y la realidad de la sociedad a la que se dirigía. El predicador valenciano intentaba transmitir a su audiencia la idea de que las virtudes curativas del nombre de Jesús están por encima del poder sanador de hierbas y medicinas e insistía en la conveniencia de utilizar la señal de la cruz y decir el nombre de Jesús devotamente para curar al enfermo de sus males. Además, estas mismas fórmulas eran válidas para curar animales y, según esto, las aves de caza también podrían beneficiarse del poder curativo del nombre de Cristo y de la señal de la cruz, como comprobamos en algunas de las obras de cetrería que se compusieron en la Baja Edad Media ${ }^{104}$.

\section{CONCLUSIONES}

La cetrería fue una práctica bien difundida y conocida entre todos los segmentos de la sociedad. Por ello, el popular y apreciado dominico Vicente Ferrer, gran observador de la realidad social, encontró en esta práctica un elemento muy valioso para construir algunos de sus ejemplos, símiles y metáforas. Sabía que hablando de aves de presa y de la forma de tratarlas y de cazar con ellas, así como de su particular comportamiento etológico, conseguiría llegar a un público muy amplio y diverso. No fue nada difícil para el predicador construir estas imágenes, pues había detrás una importante tradición de hombres de iglesia vinculados a las órdenes mendicantes, muy interesados en el conocimiento de la naturaleza, y que recopilaron y emplearon intensamente todo el conocimiento cetrero. Ferrer no hizo más que recoger una im-

102 Mateo 2, 1: "Ab Oriente venerunt Hierosolymam"; Lucas 14, 16: "Fecit caenam magnam et vocavit multos"; Mateo 1, 18: "Inventa est in utero habens [de Spiritu Sancto]". Vicente Ferrer, Sermonario de San Vicente Ferrer, pp. 732, 324 y 619, respectivamente (J. Perarnau, Aportació § 2, p. $481 ; \S 342$, p. $601 ; \S 464$, pp. 644-645).

${ }^{103}$ Lucas 10, 27: “Diliges Dominum Deum tuum ex Toto corde tuo" (J. Perarnau, Aportació $\S$ 169, pp. 542-543). P.M. Cátedra, Sermón, sociedad y literatura, pp. 440 y 442.

${ }^{104}$ Esto es lo que se recomienda en la obra de medicina para las aves de Matías Mercader, Pratica de citreria breve, ff. 19v-20r. También en J. de Sahagún, Libro de cetrería, p. 62. 
portante tradición a la que dio su particular visión y personalidad, incluyendo detalles muy precisos de lo que parece fue, más que una simple simpatía, un particular interés por el arte de la caza con aves. Esto contrasta con la escasa presencia de las aves de cetrería en los sermones de otros predicadores, especialmente del siglo XIII y anteriores. En la recopilación Index exemplorum de Tubach, de casi 5500 exempla recogidos, apenas una decena están relacionados, de alguna forma, con la cetrería. Del mismo modo, a partir de un estudio sobre el motivo de la cetrería en la literatura francesa medieval, se observa que su presencia es escasa en los exempla y, en particular, en los Contes Moralisés de Nicole Bozon. El autor de dicho estudio atribuye la falta de interés que el escritor franciscano mostró por el motivo de la caza con aves al carácter aristocrático de la misma, que se opondría al objetivo de llegar, en lengua vernácula, a un gran público ${ }^{105}$. Posiblemente, la "popularización" de la cetrería hacia el final de la Edad Media, en especial en algunos territorios de la Europa Occidental, como podría ser la Corona de Aragón, llevaron a una situación opuesta, en la que las aves de caza constituían un motivo adecuado para transmitir el mensaje religioso a la sociedad.

\section{BIBLIOGRAFÍA CITADA}

Alarcón Menargues, Félix Manel, Sobre la vida de Vicent Ferrer, valencià universal, "Ítaca" 1 (2010), pp. 249-262.

Almazan, Vincent, L'exemplum chez Vincent Ferrier, "Romanische Forschungen" 79/3 (1967), pp. 288-332.

Álvarez-Buylla Rodríguez, Miguel, El vocabulario de la cetrería en la literatura medieval, Oviedo, Universidad de Oviedo, 1975 (tesis doctoral inédita).

Ambrosio Sánchez, Manuel, Un sermonario castellano medieval: el ms. 1854 de la Biblioteca Universitaria de Salamanca, Salamanca, Ediciones de la Universidad de Salamanca, 1999, vol. I.

Beceiro Pita, Isabel, La caza y la alta nobleza bajomedieval, "Razo" 3 (1982), pp. 75-85.

Berlioz, Jacques, Le récit efficace: l'«exemplum» au service de la prédication (XIIIXV siècles), "Mélanges de l'École Française de Rome" 92 (1980), pp. 113146.

Bersuire, Pierre, Dictionarii seu repertorii moralis Petri Berchorii pictaviensis ordinis divi Benedicti, Girolamo Scoto (ed.), Venecia, Haeredem Hieronymi Scoti, 1574.

Beuchot, Mauricio, Pensamiento filosófico de San Vicente Ferrer, Valencia, Ajuntament de València, 1995.

Bover, Jaume; Rosselló, Ramon, La cetrería en las Islas Baleares: siglos XIII-XV, en Fradejas Rueda, José Manuel (ed.), La caza en la Edad Media, Tordesillas, Universidad de Valladolid, 2002, pp. 9-23.

Bover, Jaume; Rosselló, Ramon, La falconeria a les Balears s. XIII-XV, Mallorca, 2003.

Bover, Jaume; Roselló, Ramon, Alguns aspectes de la falconeria de les Balears relacionats amb la falconeria àrab, "Al-Andalus Magreb" 11 (2004), pp. 67-75.

Bremond, Claude; Le Goff, Jacques; Schmitt, Jean-Claude, L'«exemplum», Brepols, Turnhout, 1982.

Carbó, Ferran, Notes sobre les estratègies discursives a propòsit d'un sermó de sant Vicent Ferrer, en Alemany, Rafael; Ferrando, Antoni; Mesegues, Lluís

${ }^{105}$ B. Van den Abeele, La fauconnerie dans les lettres françaises, pp. 208-214. 
(eds.), Actes del IX Col-loqui Intenacional de Llengua i Literatura catalanes (Alacant-Elx, setembre 1991), Barcelona, Publicacions de l'Abadia de Montserrat, 1993, pp. 139-152.

Cátedra, Pedro M., Sermón, sociedad y literatura en la Edad Media. San Vicente Ferrer en Castilla (1411-1412). Estudio bibliográfico, literario y edición de los textos inéditos, Salamanca, Junta de Castilla y León, 1994.

Chabás, José, Las costumbres y la medicina entre los siglos XV-XVII en el litoral de Levante español reflejadas en los "sermones" de San Vicente Ferrer y en el "Spill o Llibre de les dones", de Jacme Roig, "Anales de Medicina: Medicina" 41/4 (1955), pp. 617-625.

Chamerlat, Christian Antoine de, La fauconnerie et l'art, París, ACR, 1986.

De la Torre, Ventura; Lozano, Jacinto (eds.), Gesta Romanorum. Exempla europeos del siglo XIV, Madrid, Akal, 2004.

Delcorno, Carlo, Exemplum e letteratura. Tra Medioevo e Rinascimento, Bolonia, Il Mulino, 1989.

Delgado Montoto, Manuel, Edición crítica del 'Libro de la caza de las aves' de Pero López de Ayala, Madrid, Calasancias, 2007.

Domínguez García, Avelino; Carcía Ballester, Luis (eds.); Johannis Aegidii Zamorensis, Historia naturalis, Salamanca, Junta de Castilla y León, 1994.

Eiximenis, Francesc, Art de predicació al poble, Vic, Eumo Editorial SAU, 2009.

Esponera, Alfonso (ed.), San Vicente Ferrer: vida y escritos, Madrid, Edibesa, 2005.

Esponera, Alfonso, El oficio de predicar. Los postulados teológicos de los sermones de san Vicente Ferrer, Salamanca, San Esteban, 2007.

Ferragud, Carmel, La difusión de los conocimientos médicos en la baja Edad Media a través de los sermones de san Vicente Ferrer, en Transmisión del conocimiento médico e internacionalización de las prácticas sanitarias: una reflexión histórica. Actas del XV Congreso de la Sociedad Española de Historia de la Medicina, Ciudad Real, SEHM - UCLM, 2011, pp. 461466.

Ferrando, Antoni, Vicent Ferrer (1350-1419), predicador políglota de l'Europa Occidental, en Paradigmes de la historia. Actes del Congrés Sant Vicent Ferrer i el seu temps. València 13-16 maig 1996, Valencia, Saó, 1997, vol. I, pp. 71-95.

Ferrer, Vicent, Sermonario de Perugia (Convento dei Domenicani, ms. 477), en Francisco M. Gimeno Blay; M ${ }^{a}$ Luz Mandingorra Llavata (eds.); Daniel Gozalbo Gimeno (trad.); Rebeca Sánchez Romero (col.), Valencia, Ajuntament de València, 2006.

Ferrer, Vicent, Sermons, Josep Sanchis Sivera; Gret Schib (eds.), Barcelona, Barcino, 1932-1988.

Ferrer, Vicente, Colección de Sermones de Cuaresma y otros según el Manuscrito de Ayora, Adolfo Robles Sierra (ed.), Valencia, Ajuntament de València, 1995.

Ferrer, Vicente, Sermonario de San Vicente Ferrer, Francisco M. Gimeno Blay; ${ }^{\mathrm{a}}$ Luz Mandingorra Llavata (eds.); Francisco Calero Calero (trad.), Valencia, Ajuntament de València, 2002.

Fornasiero, Serena, Struzzeria 'falconeria', in un lessico trilingue pubblicato a Venezia, "Quaderni Veneti" 34 (2002), pp. 115-128.

Fradejas Rueda, José Manuel, La cetrería en el mundo iberoamericano, "Anuario de la Asociación Española de Cetrería y conservación de Aves Rapaces" (2005), pp. 34-50.

Fradejas Rueda, José Manuel (ed.), Don Juan Manuel y el "Libro de la caza", Tordesillas, Universidad de Valladolid, 2001. 
Fradejas Rueda, José Manuel, Literatura cetrera de la Edad Media y el Renacimiento español, Londres, Queen Mary and Westfield College, 1998.

Fradejas Rueda, José Manuel, Notas léxicas: acetrería, altanería, cetrería, halconería y volatería, "Revista de filología española" 72 (1992), pp. 149-158.

Fradejas Rueda, José Manuel, Pasado y presente de la cetrería en España, Badajoz, Institución Ferial de Badajoz, 2002.

Fuster, Joan, Notes per a un estudi de l'oratòria vicentina, "Revista Valenciana de Filologia" 4/2-4 (1954), pp. 87-185.

Fuster Perelló, Sebastián (trad.), Proceso de Canonización de San Vicente Ferrer, Valencia, Ajuntament de València, 2007.

Garcia, Marinela; Arronis, Carme; Càmara, Hèctor (eds.), Libre de animals de caçar, Ms. 505 de la Biblioteca Histórica de la Universidad de Valencia, en http:// tintadellamp.ua.es/biblioteca/falconeria.xml [consulta: 07/03/2012].

García de Diego, Vicente, Voces a los animales, "Revista de dialectología y tradiciones populares" 18/3 (1962), pp. 289-338.

Gimeno, Francisco M.; Gozalbo, Daniel; Trenchs, Josep (eds.), Ordinacions de la Casa $i$ Cort de Pere el Cerimoniós, Valencia, Universitat de València, 2009.

Gordonio, Bernardo, Un manual básico de medicina medieval. Lilio de medicina, John Cull; Brian Dutton (eds.), Madison, The Hispanic Seminary of Medieval Studies, 1991.

Kemmler, Fritz, Exempla in context: a historical and critical study of Robert Mannyng of Brunne's "Handlyng synne”, Tübingen, Gunter Narr Verlag, 1984.

Llop Catalá, Miguel, San Vicente Ferrer y los aspectos socioeconómicos del mundo medieval, Valencia, Ajuntament de València, 1995.

Lecoy de la Marche, Albert, Anecdotes Historiques. Légendes et apologues tirés du recueil inédit d'Étienne de Bourbon, dominicain du XIIIe siècle, París, Librairie Renouard, 1877.

Loncke, Jeremy, La Practica canum - Le De Cane d'Albert le Grand. L'art de soigner les chiens de chasse au Moyen Age, Nogent-le-Roi, Librairie des Arts et de Métiers, 2007.

Martines, Vicent, Sant Jordi en Sant Vicent Ferrer. Reutilització d'elements tradicionals, decadència $i$ redreçament de la cavalleria, en Paradigmes de la historia. Actes del Congrés Sant Vicent Ferrer i el seu temps. València 13-16 maig 1996, Valencia, Saó, 1997, vol. I, pp. 97-108.

Martínez Romero, Tomàs, Aproximació als sermons de sant Vicent Ferrer, Paiporta, Denes, 2002.

Martínez, Romero Tomàs, Alguns aspectes de l'estructura del sermó vicentí, en Paradigmes de la historia Actes del Congrés Sant Vicent Ferrer i el seu temps. València 13-16 maig 1996, Valencia, Saó, 1997, vol. I, pp. 109-133.

Mercader, Matías, Pratica de citreria breve, Biblioteca Nacional, Ms. Res/179, en http://bdh.bne.es/bnesearch/detalle/2682764 [consulta: 07/03/2012].

Morenzoni, Francesco, Exempla et prédication: l'exemple de Jourdain de Saxe, en Berlioz, Jacques; Polo de Beaulieu, Marie Anne (dirs.), Les Exempla médiévaux: Nouvelles perspectives, París, Honoré-Champion, 1989, pp. 269-289.

Oggins, Robin, The Kings and Their Hawks: Falconry in Medieval England, New Haven - Londres, Yale University Press, 2004.

Oppitz-Trotman, Gesine, Birds, Beasts and Becket: Falconry and Hawking in the Lives and Miracles of St Thomas Becket, en Clarke, Peter; Claydon, Tony (eds.), God's bounty? The churches of the natural world, Woodbridge, Boydell \& Brewer, 2010, pp. 78-88.

Panunzio, Saverio (ed.), Bestiaris, Barcelona, Barcino, 1963 y 1964, vols. I-II.

ANUARIO DE ESTUdios Medievales, 42/1, enero-junio 2012, pp. 273-300

ISSN 0066-5061, doi:10.3989/aem.2012.42.1.13 
Parussa, Gabriella, La nature "merveilleuse » des animaux dans la predication d'un frère franciscain: Nicole Bozon et ses Metaphorae, "Reinardus" 5 (1992), pp. 143-156.

Perarnau i Espelt, Josep, Aportació a un inventari des sermons de Sant Vicenç Ferrer: temes bíblics, títols $i$ divisions esquemàtiques, "Arxiu de Textos Catalans antics" 18 (1999), pp. 479-811.

Perarnau i Espelt, Josep, Estudis i inventari de sermons de Sant Vicent Ferrer, "Arxiu de Textos Catalans Antics" 18 (1999).

Puchades i Bataller, Ramon J., Als ulls de Déu, als ulls dels homes. Estereotips morals $i$ percepción social d'algunes figures professionals en la societat medieval valenciana, Valencia, Universitat de València, 1999.

Rico, Francisco, El pequeño mundo del hombre. Varia fortuna de una idea en la cultura española, Madrid, Destino, 2005.

Robles, Adolfo, Obras y escritos de San Vicente Ferrer, Valencia, Ajuntament de València, 1996.

Rubió i Lluch, Antoni, Documents per l'història de la cultura catalana mig-eval, Barcelona, Institut d'Estudis Catalans, 2000, vol. I.

Rubio, Josep E., Salvar Aristòtil? La teologia davant la cultura pagana a la tardor medieval, "eHumanitats" 13 (2009), pp. 173-194.

Roca, Joseph Maria, Johan I d’Aragó, Barcelona, Institució Patxot, 1929.

Sahagún, Juan de, Libro de cetrería, Madrid, Cairel, 1984.

Sanchis Guarner, Manuel, Estudi preliminar, en Ferrer, Vicent, Sermons de Quares$m a$, Valencia, Albatros, 1973, vol. I., pp. 22-27.

Sanchis Sivera, Josep, Quaresma de Sant Vicent Ferrer predicada a València l'any 1413, Barcelona, Institució Patxot, 1927.

Stadler, Hermann (ed.), Albertus Magnus, De animalibus libri XXVI, Münster, Aschendorffsche Verlagsbuchhandlung, 1916-1920.

Toldrà, Albert, Sant Vicent contra el pintor gòtic. Sobre el triangle de l'expressió medieval, "Afers" 41 (2002), pp. 37-56.

Toldrà, Albert, Sant Vicent Ferrer. Debats historiogràfics, “Afers” 47 (2004), pp. 157 173.

Trombetti Budriesi, Anna Laura (ed.); Federico II, De arte venandi cum avibus, Roma - Bari, Laterza, 2002.

Tubach, Frederic C., Index Exemplorum. A handbook of medieval religious tales [FF Communications edited for the folklore fellows, vol. LXXXVI, n. 204], Helsinki, Academia Scientiarum Fennica, 1981.

Vallés, Juan, Libro de acetrería y montería, José Manuel Fradejas Rueda (ed.), Madrid, Círculo de Bibliofilia Venatoria, 1994.

Van den Abeele, Baudoin, L'allégorie animale dans les encyclopédies latins de Moyen $\hat{A} g e$, en Berlioz, Jacques; Polo de Beualieu, Marie Anne (dirs.), L'animal exemplaire au Moyen Âge. Ve-XVe, Rennes, Presses Universitaires de Rennes, 1999, pp. 123-143.

Van den Abeele, Baudouin, La fauconnerie dans les lettres françaises du XII au XIV siècle, Lovaina, Leuven University Press, 1990.

Van den Abeele, Baudouin, La fauconnerie au Moyen Âge, París, Klincksieck, 1994.

Van den Abeele, Baudouin, La littérature cynégétique, Turnhout, Brepols, 1996.

Van den Abeele, Baudouin, Le faucon sur la main. Un parcours iconographique médiéval, en Paravicina Bagliani, Agostino; Van den Abeele, Baudouin (eds.), La Chasse au Moyen Age: Société, traités, symboles, Florencia, Sismel, 2000.

Velasco, Alberto, De València a Vannes: culte, devoció i relíquies de sant Vicent Ferrer, "Acta Historica et Archaeologica Mediaevalia" 29 (2008), pp. 395 436.

ANUARIO De Estudios Medievales, 42/1, enero-junio 2012, pp. 273-300

ISSN 0066-5061, doi:10.3989/aem.2012.42.1.13 
Von Moos, Peter, L'exemplum et les exempla des prêcheurs, en Berlioz, Jacques; Polo de Beaulieu, Marie Anne (dirs.), Les Exempla médiévaux: Nouvelles perspectives, París, Honoré-Champion, 1989, pp. 67-81.

Williams, Jane Welch, Bread, Wine \& Money. The Windows of the Trades at Chartres Cathedral, Chicago - Londres, The University of Chicago Press, 1993.

Ysern i Lagarda, Josep-Antoni, Sant Vicent Ferrer: Predicació i societat, "Revista de Filologia Romànica” 20 (2003), pp. 73-102.

Ziegler, Joseph, Medicine and religion c. 1300, Oxford, Clarendon Press, 1998.

Zúñiga y Sotomayor, Fadrique, Libro de cetreria de caça de açor, Salamanca, 1565 (edición facsímil: Valladolid, Maxtor, 2002).

Fecha de recepción del artículo: marzo 2012

Fecha de aceptación y versión final: abril 2012 